\title{
Risk Preferences and Pesticide Use By Cotton Farmers in China
}

\author{
Elaine M. Liu ${ }^{*}$ \\ University of Houston \\ JiKun Huang \\ Center for Chinese Agricultural Policy, Chinese Academy of Sciences
}

December, 2012

\begin{abstract}
$\underline{\text { Abstract }}$
Despite insect-resistant $\mathrm{Bt}$ cotton has been lauded for its ability to reduce the use of pesticides, studies have shown that Chinese Bt cotton farmers continue to use excessive amounts of pesticides. Using results from a survey and an artefactual field experiment, we find that farmers who are more risk averse use greater quantities of pesticides. We also find that farmers who are more loss averse use lesser quantities of pesticides. This result is consistent with our conceptual framework and suggestive evidence where farmers behave in a loss averse manner in the health domain and place more weight on the importance of health over money in the loss domain.
\end{abstract}

Keywords: risk preferences, prospect theory, pesticide use

\footnotetext{
*Corresponding author; Email: emliu@uh.edu
} 


\section{Introduction}

Modern agricultural biotechnology has made a great deal of progress over the past two decades in significantly increasing productivity and living standards in developing countries. These advancements have introduced a wide array of genetically modified crops that are insect resistant, virus resistant, drought resistant, and even nutrient enriched. Take genetically modified Bacillus thuringiensis (Bt) cotton as an example. Prior to the invention of Bt cotton, farmers were forced to choose between letting cotton bollworms (the primary cotton pest) damage their cotton yields or sacrificing their own health by spraying their crops with a greater quantity of pesticides. Bt cotton was devised specifically to counter bollworm infestations and has been scientifically proven to be effective in pest resistance (Qaim \& Zilberman, 2003; Qaim, Subramanian, Naik \& Zilberman, 2006; Huang, et al., 2002b). Emboldened by this scientific evidence, policy makers around the world have encouraged the adoption of Bt cotton. However, several studies find that farmers have continued to use excessive amounts of pesticides even after they adopted pest-resistant Bt cotton (Huang, et al., 2002a; Pemsl \& Waibel, 2005; Yang et al., 2005). ${ }^{1}$ These findings present a puzzle as to why farmers would deviate from profit-maximizing behavior to spray excessive amounts of pesticides, especially considering the fact that spraying pesticides is detrimental to their health. Liu (2011) has suggests that Chinese cotton farmers were slow to adopt Bt cotton because of their risk preference. It is possible that farmers who are more risk averse could also be using more pesticides after adopting Bt cotton. This paper uses the same dataset as Liu (2011) to investigate whether Chinese cotton farmers' pesticide-use decisions are correlated with their risk preferences.

There is an extensive theoretical literature where farmers' risk preferences play a role in

\footnotetext{
${ }^{1} \mathrm{Bt}$ cotton is not a fix-all solution as it only targets cotton bollworm. Pesticide is still essential to cotton production post Bt adoption. However, a few papers (Huang, et al., 2002a; Pemsl \& Waibel, 2005; Yang et al., 2005) find that farmers are using nearly 3 times more pesticide than the optimal profit maximizing level.
} 
agricultural production decisions (Just and Zilberman 1983; Feder 1980). In determining the relationship between agricultural decisions and risk preferences, most of the empirical studies in the literature typically have two approaches when estimating risk aversion. One is to rely on the assumption of objective function and advanced econometric technique to impute the coefficient of risk aversion that will fit the model (Antle, 1988; Saha, Shumway, \& Talpaz, 1994; Chavas \& Holt, 1996). For example, if a farmer deviates from profit-maximizing production input choices, the structural approach would conclude that it is due to individual risk preference and impute the coefficient of risk aversion. As suggested by Just and Lybbert (2009) and Just (2008), the assumption of a utility function form and arbitrary heuristics could cause bias when estimating individual risk aversion. On the other hand, some studies use wealth as a proxy for risk aversion (Laffont and Matoussi, 1995; Ackerberg and Botticini, 2002; Dubois, 2002; and Fukunaga and Huffman, 2009). Bellemare and Brown (2010) comment that it could be problematic when wealth is being used as a proxy for risk aversion, as it could potentially undermine the role of risk preferences in farming decisions. One contribution to the existing literature is that all risk preference parameters used in the analysis are being elicited from artefactual field experiments. ${ }^{2}$

Starting from Binswanger's $(1980,1981)$ seminal papers, it is not uncommon to elicit risk preference where farmers are the subjects of the experiments. However, there exists a longstanding debate regarding the external validity of game experiments. ${ }^{3}$ In this study, we first elicit farmers' risk preference from an experiment, and we extend their game behaviors to the agricultural decisions. The findings from this study bridge the gap between lab experiments and real world behavior. Similar to research by List (2003), Schechter (2007), and Fehr and Goette

\footnotetext{
${ }^{2}$ We adopt the terminology artefactual field experiment from Harrison and List (2004). Artefactual field experiments are conventional lab experiments but are done with nonstandard subjects. Hereafter, we will refer to it as the experiment.

${ }^{3}$ See Samuelson (2005) for discussion.
} 
(2007), the findings from this study suggest that experiment results can predict real world decisions in the case of Chinese cotton farmers' pesticide use.

Before eliciting the risk preference using the experiment, we first need to decide on the form of the utility function. The common approach to characterize individual risk preference is to use expected utility (EU), in which risk aversion is the sole parameter for determining the curvature of the utility function. On the other hand, in prospect theory (Kahneman \& Tversky, 1979) (PT), the shape of the utility function is jointly determined by risk aversion, loss aversion (which measures one's sensitivity to loss compared to gain), and nonlinear probability weighting (i.e., the individual tendency of overweighting small [large] probabilities and underweighting large [small] probabilities). As suggested in earlier agricultural economics research, if farmers follow safety-first principles by setting a target income and minimizing the probability of severe yield loss below that income (Moscardi \& de Janvry, 1977; Young, 1979), then it is likely that farmers' risk preferences will be best captured by prospect theory instead of neoclassical utility theory. ${ }^{4}$ Ex ante, EU or PT could act as a potential theory for explaining the cotton farmers' decision making processes; however, it is not clear which theory is more appropriate. Therefore, we use an experimental design modeled after that of Tanaka, Camerer, and Nguyen (TCN) (Tanaka et al., 2010). The major advantage of TCN's design is that it allows the experiment's results to determine whether EU or PT better fits the farmers' decision making processes. It allows us to elicit three risk preference parameters - coefficient of risk aversion, loss aversion, and nonlinear probability weighting — without rejecting outright the use of EU theory. Our survey covers 320 cotton farmers from 16 villages across eight counties in four provinces in China in 2006. We collect information on household characteristics, individual characteristics,

\footnotetext{
${ }^{4}$ The applications of these two concepts, "safety-first rule" and "loss aversion," can be found in behavioral finance studies (see Campbell \& Kräussl, 2007; Camerer \& Kunreuther, 1989; Polkovnichenko, 2005).
} 
and detailed plot information for the 2006 harvest and planting season. We relate the farmers' elicited risk preferences to their pesticide use while controlling for farm and individual characteristics.

Before interpreting our results, in order to understand how each of the risk preference parameters would affect optimal pesticide use, we set up a conceptual framework in which farmers' utility is a function of income as well as their health. By using more pesticide, farmers would prevent loss of income but would have to sacrifice their health due to the danger of pesticide poisoning. Therefore, depending on one's coefficient of risk aversion, loss aversion and one's reference points for health and income, the optimal pesticide use would differ.

Our main finding is that controlling for village fixed effects, farmers who are more risk averse use greater quantities of pesticides. If the average farmer from our sample became risk neutral, he would spray approximately $13 \%$ less pesticides — a reduction in pesticide use equivalent to the effect of 6 additional years of education). ${ }^{5}$ Combining with the finding from Liu's (2010) paper on Bt cotton adoption, we can conclude that more risk averse farmers not only adopt Bt cotton later, but they also continue to use higher level of pesticide post adoption. Therefore, wealth accumulation associated with this technological advancement is negatively correlated with farmers' risk aversion. We also find that farmers who are more loss averse use lesser quantities of pesticides. It may seem surprising at first glance, but it is consistent with our conceptual framework and suggestive evidence where farmers behave in a loss averse manner in the health domain and yet place more weight on the importance of their health over the importance of money in the loss domain.

We find that more educated farmers seem to better understand the advantages of using Bt cotton since it requires less pesticides than regular cotton. For every additional year of

\footnotetext{
${ }^{5}$ The average farmer in the sample is risk averse with a coefficient of risk aversion equal to 0.48 .
} 
education, farmers reduce pesticide use by $0.56 \mathrm{~kg}$ per hectare $(\sim 2 \%)$. Several other hypotheses have been put forth by others to explain the overuse of pesticide, including the deterioration of the bollworm-resistant quality of Bt cotton seeds, the existence of counterfeit Bt cotton seed, the incorrect information supplied by extension agents and the rise of secondary pests. In our study, with our regression specifications, controlling for village fixed effects, we find no evidence supporting these alternative hypotheses. ${ }^{6}$

This paper proceeds as follows. Section 2 provides background on Bt cotton. Section 3 describes the experiment and dataset and provides some summary statistics on farmers' characteristics and describes the experimental design. Section 4 provides background on pesticide use and the conceptual framework. Section 5 describes the econometric framework and regression results for pesticide use. Section 6 concludes.

\section{Background}

China is one of the largest cotton producers in the world. Unlike commercial cotton farmers in the United States, Chinese cotton farmers are generally subsistence farmers who are more risk averse, less tolerant of pest infestations, and place the highest priority on resolving severe pest problems (Bentley \& Thiele, 1999; Pray et al., 2002). During the early 1990s, many Chinese cotton farmers experienced failures in controlling bollworm damage to their crops due to frequent outbreaks of increasingly pesticide-resistant bollworm infestations. In an attempt to ameliorate the bollworm problem, the provincial governments in certain regions of China began commercializing Bt cotton seeds in 1997. ${ }^{7}$ Bt cotton seeds are planted in a similar fashion to

\footnotetext{
${ }^{6}$ It is still possible that these hypotheses can explain cross-village variations of pesticide use. For the purpose of our paper, investigating the role of risk preferences, it is essential to control for village fixed effects for the following reasons. First, a village can play a role in determining one's risk preferences (e.g. a particular village may have more poor quality, less arable land), hence people in the village are more risk averse. Second, if we do not have village-fixed effect, we need a lot more information about the village characteristics that could possibly affect pest severity, which is missing from our survey.

${ }^{7}$ It was a rolling decision. In some provinces Bt cotton was approved in 1998.
} 
traditional cotton seeds, but Bt cotton seed carries the Bt toxin which targets the cotton bollworm. Using data collected in 2001, Huang, et al. (2002b) found that Bt cotton adoption leads to a significant decrease in pesticide use. Bt cotton farmers reduce their total pesticide expenditure by $82 \%$. Chinese scientists tested bollworm pests with Bt cotton and concluded that bollworms found in China's cotton fields had not yet become resistant to Bt cotton (Wu, 2007). Tracking bollworm population over a decade in 6 provinces in China, $\mathrm{Wu}$, et al. (2008) have also shown that populations of bollworm larvae and bollworm eggs have continually decreased from 1997 to 2007.

While the bollworm's lack of resistance to Bt cotton is encouraging, significant problems still exist. Primarily, Chinese cotton farmers are well known for using excessive amounts of highly toxic pesticides, and this practice has continued even after the adoption of Bt cotton (Huang, et al., 2002a; Pemsl \& Waibel, 2005; Yang et al., 2005). Huang, et al. (2002a) find that Bt cotton farmers applied $11.8 \mathrm{~kg}$ per hectare when the optimal pesticide use ranges from $0.4 \mathrm{~kg}$ per hectare to $4.2 \mathrm{~kg}$ per hectare. ${ }^{8}$ Pemsl and Waibel (2005) find that the optimal pesticide input level was about $5 \mathrm{~kg}$ per hectare in 2004, but that Chinese farmers applied, on average, $14 \mathrm{~kg}$ of pesticides per hectare. The problem of pesticide overuse is further exacerbated by the fact that nearly $40 \%$ of the pesticides used by Chinese cotton farmers contain active ingredients that are classified as extremely or highly hazardous (classes $1 \mathrm{a}$ or $1 \mathrm{~b}$ ) by the World Health Organization (WHO). ${ }^{9}$ There are an estimated 400 to 500 Chinese cotton farmers who die every year from pesticide poisoning (Conko \& Parkash, 2004). In our sample, 27\% of farmers reported that they have experienced pesticide poisoning and $38 \%$ of them reported that someone in their family has

\footnotetext{
${ }^{8} 0.4 \mathrm{~kg} / \mathrm{ha}$ is based on an estimation using the Cobb-Douglas production function. $4.2 \mathrm{~kg} / \mathrm{ha}$ is based on an estimation that uses a Weibull damage control function.

${ }^{9}$ The WHO classifies insecticides into four classes of toxicity. Class 1a is extremely hazardous (highest toxicity).

Class $1 \mathrm{~b}$ is highly hazardous. Class 2 is moderately hazardous. Class 3 is slightly hazardous.
} 
experienced pesticide poisoning.

A question that naturally arises is: if Bt cotton has proven its resistance to the cotton bollworm and if farmers know that spraying pesticides is detrimental to their health, why would farmers spray excessive quantities of pesticides? The farmers' uncertainty about the quality of Bt cotton seeds could be a significant factor in their overuse of pesticides. Existing studies have found that the quality of Bt cotton seeds varies dramatically. Pemsl (2006) collected leaves from cotton farmers in Shandong and found that some of the so-called "Bt" cotton leaves do not contain the Bt trait that is essential to making the cotton plant resistant to the bollworm.

Due to the high demand for Bt cotton seeds, it is not surprising that some individuals are trying to exploit the situation for profit through various nefarious means. Therefore, some lowerquality seeds have permeated the market through different channels. For example, some firms and local research institutions release $\mathrm{Bt}$ cotton seeds into the market before obtaining government approval (Yang et al., 2005). Farmers also reproduce the trademarked Bt cotton seeds via on-farm propagation despite evidence that these self-propagated seeds are of lower quality (Pray et al., 2002). Some seed companies simply repackage their conventional cotton seeds to sell as authentic Bt cotton seeds with brand labels and logos (Louyang Agricultural News, 2003). There were an estimated 140 genetically modified cotton seed varieties available in 2004, making it difficult for farmers to know which seeds are effective Bt cotton seeds a priori (Pray et al., 2006). One might think that farmers could learn from their own experience or from others over time about the quality of seeds from various sources. However, given that the severity of pest infestation varies greatly over time and across plots, the amount of learning accumulated could be limited.

One other reason why farmers may be using excessive amounts of pesticides is proposed 
by Wang, Just, and Pinstrup-Anderson (2006) who suggest that the population of secondary pests, mainly mirids, has been slowly rising. Wang et al. (2006) examine Chinese cotton farmers' pesticide use using survey data from 2004 and find that $\mathrm{Bt}$ cotton farmers use less pesticides to prevent bollworms, but spray more pesticides in order to target mirids, relative to non-Bt cotton farmers. Furthermore, Lu, et al., (2010) find some evidence suggesting that the secondary pest, mirids, have increased in population density, in particular in areas where Bt cotton adoption is common.

While many of the above reasons are plausible explanation, in our study we are focusing on the within-village variation in pesticide use across farmers. In our empirical analysis, we control for village fixed effect, which would also control for village-specific pest severity and the rising of the secondary pest in the village. Village fixed effects should also control for the potential effects from skewed recommendation of extension agents. Unless the individualspecific error term is correlated with our elicited risk preference, our results on risk preferences should remain unbiased. We will have more discussion in detail in Section 5.

\section{Data}

\subsection{Bt Cotton Survey}

The Bt cotton survey was designed and collected by the Center for Chinese Agricultural Policy (CCAP), a government-affiliated research agency, in the winter of 2006. Four provinces (Shandong, Hebei, Henan, and Anhui) with high Bt cotton adoption rates and similar cotton growing seasons (April-October) were selected. CCAP selected two counties per province and two villages per county, and randomly selected 20 households in each village. The CCAP team compensated each participating household 10 yuan for completing the survey (equivalent to onethird of a daily wage). We interviewed the head of each household or whoever was most 
responsible for the farming activities. In addition, we obtained detailed information on inputs and outputs used in each cotton plot, perceived pest infestation, incidence of pesticide poisoning, and past agricultural training experience. Most farmers are responsible for multiple plots, as arable land for farming is assigned by the government. Out of the 945 cotton plots belonging to 320 farmers, 930 of them are used to grow Bt cotton and the remaining 15 are used to grow conventional cotton. ${ }^{10}$

The summary statistics at the household level are presented in Table 1. The average interviewee is about 50 years old and has completed 7 years of education. The average household in the sample is assigned 0.59 hectares of farmland. In the region where we collected the dataset, cotton is the major cash crop and is planted on 0.54 hectares of farmland per household with farmers typically practicing rotational cropping with wheat, the primary grain crop $(0.33$ hectares). Our sample spends most of their time on the farm, and when production on the farm stops, they perform a limited amount of off-farm work. Ownership of a set of durable goods is used as a proxy for wealth in 2006.

\section{[Insert Table 1 About Here]}

Table 2 presents the summary statistics at the plot level, breaking them down by Bt versus non-Bt cotton. Bt cotton is more expensive than traditional cotton, but farmers who grow Bt cotton spray less pesticides and experience higher yields. In this paper, wealth is proxied by the price of durable goods owned per capita and Bt cotton farmers are statistically wealthier than traditional cotton farmers. However, without a baseline survey prior to adoption, we cannot conclude any causality on whether the differential wealth accumulation is due to the planting of Bt cotton or as a cause of difference in seed choices.

\footnotetext{
${ }^{10}$ In the winter of 2007, the CCAP collected cotton seeds from a subset of our sample. When researchers tested the seeds in the lab, they found that farmers often misreported the Bt versus non-Bt status of their seeds. Some so-called "non-Bt" seeds in fact contained the Bt gene and vice versa.
} 


\section{[Insert Table 2 About Here]}

Ideally, we would like to have detailed data on pesticide use and we need to know the severity of pest problems in the region; then we would be able to use a production function to estimate whether farmers overuse specific pesticides. To do so, however, we would need information on the pesticides' active ingredients. However, China's pesticide market is extremely fragmented; in our survey alone, we found more than 50 different pesticide brands/formulations. Many farmers purchase pesticides that are blends of various brands. It is also difficult to classify these pesticides by the WHO's toxicity measures because most of the pesticides' packaging does not contain information on active ingredients. Therefore, in our analysis, we will only use the total amount and total costs of the pesticides applied by the farmers as a dependent variable.

We also collected information on pesticide poisoning. Farmers were asked if over the previous 10 years anyone in their household had experienced any health impairments after mixing and spraying pesticides. Twenty-nine percent (94) reported that they had experienced at least one symptom of pesticide poisoning since 1996, with the most frequently reported symptoms being vomiting (59\%), headaches or dizziness (53\%), skin irritation (26\%) and restlessness $(16 \%) .{ }^{11}$ Forty percent reported that one of their family members has experienced pesticide poisoning since 1996. We also asked the farmers to report any costs associated with these health impairments. Seventy-six farmers reported having some cost associated with pesticide poisoning with the average medical cost and imputed labor cost being 165 yuan (approximately five days worth of wages) per farmer. ${ }^{12}$

\subsection{Experimental Design}

The Chinese cotton farmers were asked to participate in an experiment after the

\footnotetext{
${ }^{11}$ The percents add up to over 100 because some farmers reported multiple symptoms.

1276 farmers reported having some costs due to pesticide poisoning.
} 
conclusion of their interviews. We conducted an experiment modeled after that of Tanaka, Camerer, and Nguyen (2010). ${ }^{13}$ TCN's experiment is similar to Holt and Laury's (2002) which offers subjects a series of pair-wise lotteries of both risky and safe options presented in Table 3. Take Row 1 Series 1 in Table 3 for example: if farmers have chosen lottery A, there is a 30\% chance of winning 20 Yuan and a 70\% chance of winning 5 Yuan; if they have chosen lottery B, the riskier option, they have a $10 \%$ chance of winning 34 Yuan and a $90 \%$ chance of winning 2.5 Yuan. One would note that within each series, the safe option does not change, but the expected payoff of the risky option increases as we move down the rows.

\section{[Insert Table 3 About Here]}

Farmers were asked to choose either lottery A or lottery B for each row. More specifically, they were asked at which row, from Row 1 to Row 14, would they switch from lottery A to lottery B for each series. ${ }^{14}$ Farmers were told that one of the rows would be chosen at random. There is a bag of 10 numbered balls and depending on whether they have chosen lottery A or lottery B in each row, the numbered ball they draw randomly will determine the payoff. They were presented with 35 questions separated into 3 series (see the Online Appendix for answer sheets used in the game). ${ }^{15}$

Following TCN's model, we assume a utility function of the following form:

\footnotetext{
${ }^{13}$ Out of 320 farmers, only 5 decided not to participate in the experimental part and they own 11 plots. The more detailed description of the experiment instructions and imputation of risk preference parameters can be found in the Appendix.

${ }^{14}$ The option of choosing either all A or all B is also available. This method of eliciting switching point is being referred to as monotonic switching. This method assumes rationality of the subjects and eliminates any inconsistent behavior of subjects.

${ }^{15}$ Online Appendix can be found on Liu's homepage.
} 


$$
\begin{aligned}
& U(x, p ; y, q)= \begin{cases}v(y)+\pi(p)(v(x)-v(y)) & x>y>0 \text { or } x<y<0 \\
\pi(p) v(x)+\pi(q) v(y) & x<0<y\end{cases} \\
& \text { where } v(\mathrm{x})=\left\{\begin{array}{ll}
x^{1-\sigma} & \text { for } x>0 \\
-\lambda(-x)^{1-\sigma} & \text { for } x<0
\end{array} \text { and } \pi(p)=\exp \left[-(-\ln p)^{\alpha}\right]\right.
\end{aligned}
$$

where $\mathrm{p}$ and $\mathrm{q}$ are the probability of the event with monetary outcome $\mathrm{x}$ and $\mathrm{y}$, respectively. $\mathrm{v}(\mathrm{x})$ is the value function and the functional form would depend on whether $\mathrm{x}$ is below zero or not. $\lambda$ measures the sensitivity to loss versus gain. Bigger $\lambda$ would indicate one is more sensitive to loss over gain. $\sigma$ is the standard measure of risk aversion. The higher the sigma, the higher the degree of risk aversion; $\pi(\mathrm{p})$ is the probability weighting function adapted from Prelec (1998). If $\alpha<1, \pi(\mathrm{p})$ has an inverted $S$-shape-individuals overweight small probabilities and underweight large probabilities. ${ }^{16}$ One major advantage of the TCN method is that while TCN incorporates PT, it does not reject EU outright. If $\alpha=1$ and $\lambda=1$, then utility function reform would reduce to the standard expected utility function TCN can fall back upon. Using the farmers' three switching points from the three series and the utility function form assumption, we can impute the farmers' risk preference parameters. The method of imputation can be found in the Appendix. We reject the null hypothesis that $\lambda=1$ and $\alpha=1$ at the $1 \%$ level. The summary statistics of individual risk preference measures are provided in Table $1 .{ }^{17}$

\section{Decisions about Pesticide Use}

\subsection{Literature on Pesticide Use}

\footnotetext{
${ }^{16}$ In the literature of probability weighting, Gonzalez and $\mathrm{Wu}$ (1999) find that the inflection point of probability weighting functions occurs at about $30 \%$. In other words, if probability is less than $30 \%$, it is considered a small probability event.

${ }^{17}$ For more detailed distribution and analysis of the risk preference parameters used in this paper, see Liu (2011).
} 
There is an extensive literature in agricultural economics regarding the optimal level of pesticide use. The most common approach in estimating the optimal pesticide use (or any input) is to use the Cobb-Douglas production function and damage control framework to assess the input substitution and marginal pesticide productivity (Lichtenberg \& Zilberman, 1986). ${ }^{18}$ This approach usually takes the form:

$$
Y=a_{o}\left[\prod_{i=1}^{n}\left(x_{i}^{D}\right)^{\beta_{i}}\right] * G\left(x^{p}\right)^{\gamma}, \quad \operatorname{Eq}(2)
$$

where $\mathrm{Y}$ is the yield; $\mathrm{a}_{o}\left[\prod_{i=1}^{n}\left(x_{i}^{D}\right)^{\beta_{i}}\right]$ is the Cobb-Douglas production function, where $x_{i}^{D}, i=$ $1,2, \ldots n$ are production inputs such as labor, fertilizer, etc.; $\beta_{\mathrm{i}}$ is a vector of the coefficients; $\mathrm{G}\left(x^{p}\right)^{\gamma}$ is the damage control function, where $\mathrm{x}^{\mathrm{p}}$ is a vector of damage control agents such as pesticide, herbicide, a Bt cotton binary variable, etc. The key to this function form is that pesticide, a damage control agent, does not enter the production function. ${ }^{19}$

This approach has been pursued by Pemsl and Waibel (2005) and Huang, et al. (2002a) to study patterns of pesticide use among Chinese farmers and to evaluate the effectiveness of each input on increasing yields. For the rest of this section, we focus specifically on literature that treats Chinese Bt cotton farmers' pesticide use.

\footnotetext{
${ }^{18}$ One might think the target input model by Jovanovic and Nyarko (1994) and Foster and Rosenzweig (1995) may be an alternative to the Cobb-Douglas production function in estimating the optimal pesticide use. The key idea of the target input model is that as time goes by, the agent develops more expertise and become more productive. In our case, farmers could possibly be learning over time about the optimal pesticide use. Without incorporating risk preferences, the target input model would probably predict 1) as farmers gain more experience, their pesticide use would be converging to the optimal pesticide level; 2) if we look at a cross section of evidence, we would find that farmers who have longer experience with Bt cotton would be using less pesticide. We cannot test 1) since we only have a cross-sectional survey. We do not have the ability to trace one's pesticide use pattern over time. As for 2), Liu (2011) finds that the time to adoption, thus farmers' experience using Bt cotton, is also correlated with one's risk preferences. If we find evidence that farmers who have longer experience with Bt cotton use less pesticide, it will be difficult to disentangle the effect of experience from one's risk preferences.

${ }^{19}$ This approach to calculating optimal pesticide use assumes that farmers are risk neutral. However, in actuality, as we discovered from the lottery experiment, most farmers are risk averse. Using a reduced-form approach, we are going to include farmers' risk preferences. One could imagine instead of maximizing over the Y (yield), farmers are maximizing their utility which is a function of the yield. We provide some conceptual framework of the role of risk preferences in the next section.
} 
The main limitation of the aforementioned structural approach is that it does not account for endogenous pesticide use in the production function. When pest infestation is serious, farmers would spray more pesticide but at the same time, yield could be lower as well. Huang, et al. (2002a) use two-stage least square regressions to estimate yields and pesticide use. In the first stage, they employ determinants such as education and age to estimate pesticide use, while using perceived yield loss, price of pesticides, and talks with extension agents as instruments. In the second stage, they estimate Equation (2) using the predicted pesticide use. Their estimate of optimal pesticide use for Bt cotton farmers in 1999 is $1.2 \mathrm{~kg}$ per hectare to $4 \mathrm{~kg}$ per hectare, depending on the specification of the damage function, while actual pesticide use at the time was $11.8 \mathrm{~kg}$ per hectare. The main problem with Huang, Hu, et al.'s method of estimation is that the instruments may not satisfy the exclusion restriction. For example, both perceived yield loss and communication with extension agents are very likely to be correlated with education, which also affects pesticide use. In addition, since the use of counterfeit Bt cotton seeds has been rampant, farmers' self-reports of Bt cotton status may not be accurate, thus undermining the imputed effectiveness of Bt cotton.

Unlike Huang, et al. (2002a), Pemsl and Waibel (2005) take a step forward by refining what Bt cotton truly represents in the damage control function. Pemsl and Waibel collected leaves from each plot in order to test the leaves' toxin levels, instead of Huang, et al.'s (2002a) approach using a binary variable indicating Bt cotton in the damage control function. Using the more accurate measure of Bt toxin, Pemsl and Waibel (2005) also conclude that Chinese cotton farmers use an excessive amount of pesticides. They find that the optimal pesticide input level was about $5 \mathrm{~kg}$ per hectare in 2004, but that Chinese farmers applied, on average, $14 \mathrm{~kg}$ of pesticides per hectare. In sum, both Huang, et al. (2002a) and Pemsl and Waibel (2005) find that 
Chinese cotton farmers are using nearly three times more pesticide than optimal.

Several hypotheses have been formulated to explain the use of excessive pesticides (Huang, et al., 2002b; Pemsl, 2006; Yang et al., 2005). One hypothesis is related to the agricultural extension agents who are hired by the government to educate farmers about the pesticides and new farming technology. Since agricultural extension agents' salaries are often tied to the profits of pesticide sales, they are incentivized to advise farmers to use pesticides even when it is unnecessary (Huang, et al., 2002b). Pemsl (2006) proposes that the uncertainty associated with the quality and effectiveness of both pesticides and Bt cotton seeds leads to farmers overusing pesticides. Yang et al. (2005) find that many farmers often confuse the larvae of cotton bollworms with those of other insects; it is possible that their vivid memories of the high bollworm infestation years and the crop losses sustained during those bollworm outbreaks could lead farmers to overuse pesticides on their Bt cotton crops. Or the worse scenario, which has not been linked directly to the overuse of pesticide: Wang et al. (2006) and $\mathrm{Lu}$, et al. (2010) find some evidence suggesting that a secondary pest, mirids, may be on the rise especially in $t$ areas where there is high use of $\mathrm{Bt}$ cotton.

The preceding studies on Chinese cotton farmers' pesticide use patterns have only been able to offer some suggestive hypotheses without being able to test them with an econometric model. One important difference between these and the current study is that none of these aforementioned studies have incorporated farmers' risk preferences into the decision making process. When uncertainty in production exists, farmers' utility-maximizing choices would differ from profit-maximizing decisions if they are not risk neutral. If farmers are risk averse, the decision of overusing pesticide may not be suboptimal. Therefore, farmers' risk preferences should play an important role in deciding the quantity of pesticides they use. 


\subsection{Conceptual Framework}

In this section, we will set up a simple conceptual framework to demonstrate how each of the risk preference parameters could affect one's optimal pesticide use if both health and income are part of the utility function. Suppose for an individual farmer $i$, the farmer's utility function is an increasing function of the income $\left(Y_{i}\right)^{20}$ and health stock $\left(\mathrm{H}_{\mathrm{i}}\right)$, we have the additive utility as follows : $U_{i}=U\left(H_{i}, Y_{i}\right)=U_{H}+U_{Y}$. We take a simplistic view that $H_{i}$ is a consumption good and is independent of the level of $Y_{i}$. Subscripts $(\mathrm{H}, \mathrm{Y})$ denote whether a variable is for health or monetary domain. The TCN experiment and its utility functional form (Equation 1) are written for a monetary domain. Here we assume that both $U_{H}, U_{Y}$ take the prospect theory functional form as illustrated in Equation $1^{21}$. We further assume that these risk preference parameters $(\sigma, \alpha, \lambda)$ are the same (or highly correlated) in both health and monetary domains. $^{22}$ In other words, one's coefficient of loss aversion in the monetary domain, $\lambda_{\mathrm{Y}}$, is the same as his coefficient of loss averse in the health domain, $\lambda_{\mathrm{H}}$; we make similar assumptions for for nonlinear probability weighting and coefficient of relative risk aversion: $\alpha_{H}=\alpha_{Y}$ and $\sigma_{H}=\sigma$ Y.

In Equation 1 and TCN experiment, the reference point for income is assumed to be zero. In the case of Chinese farmers, each of the health and income domains would have different reference points. As $U_{H}$ has a reference point $\left(H_{0}\right)$ in the health domain, $U_{Y}$ would have a reference point $\left(Y_{0}\right)$ in the income domain. Again, only when an outcome is below the

\footnotetext{
${ }^{20}$ One can also assume that $\mathrm{Y}$ is yield, and incorporate price of cotton in the utility function. Given that there is almost no variation in cotton price within villages, we just use $\mathrm{Y}$ as income for the sake of simplicity.

${ }^{21}$ This is not the first paper to incorporate prospect theory in health related decision making. Bleichrodt and his coauthors have a series of papers exploring the interaction between loss aversion/nonlinear probability weighting in medical decision making (Bleichrodt et al., 2001; Bleichrodt \& Pinto, 2002). In Bleichrodt et al. (2001) elicit individual preference over health outcomes and they find the coefficient of loss aversion is between 2.17-3.06, which is similar to our measures of loss aversion.

${ }^{22}$ This assumption that risk preference across domain is correlated has been tested by Dohmen et al. (2010). They find that a general risk preference question (i.e. willingness to take risks on an 11-point scale) can predict risky behavior in various domains including health and monetary domains.
} 
reference point, the loss aversion parameter would affect one's utility.

Suppose there are only two possible outcomes for health $(\bar{H}, \underline{H})$ and for income $(\bar{Y}, \underline{Y})$.

$\bar{H}>\underline{H} ; \quad \bar{Y}>\underline{Y}$. We can rewrite utility as $U_{i}=U\left(H_{i}, Y_{i}\right)=U_{H}+U_{Y}=U\left(\bar{H}, \overline{p_{H}} ; \underline{H}, \underline{p_{H}}\right)+$ $U\left(\bar{Y}, \overline{p_{Y}} ; \underline{Y}, \underline{p_{Y}}\right)$ where $\overline{p_{H}}, \underline{p_{H}}, \overline{p_{Y}}, \underline{p_{Y}}$ are the corresponding probabilities of $\bar{H}, \underline{H}, \bar{Y}, \underline{Y}$ respectively, such that $\overline{p_{H}}+\underline{p_{H}}=1$ and $\overline{p_{Y}}+\underline{p_{Y}}=1 . \overline{p_{Y}}$ would depend only on $x^{p}$ and $S$ where $x^{p}$ is the amount of pesticide use. S indicates severity of pest infestation. ${ }^{23} \frac{d \overline{p_{y}}}{d s}<0, \frac{d \overline{p_{y}}}{d x^{p}}>$ $0, \frac{d^{2} \overline{p_{y}}}{d\left(x^{p}\right)^{2}}<0$ and $\frac{d^{2} \overline{p_{y}}}{d s^{2}}<0$. The more pesticide one uses, the more the probability of high income, $\overline{p_{Y}}$, increases. On the other hand, the more pesticide one uses, the chance of being poisoned, $\underline{p_{H}}$, increases. Thus, $\frac{d \overline{p_{H}}}{d x^{p}}<0$ and $\frac{d \underline{p_{H}}}{d x^{p}}>0$. The optimal pesticide use, $\left(x^{p *}\right)$, would depend on the risk preference parameters $\sigma, \lambda$ and $\alpha, \mathrm{S}, \bar{H}, \underline{H}$ and $\bar{Y}, \underline{Y}$.

To illustrate how the risk aversion parameter $\sigma$ affects optimal pesticide use $\left(x^{p *}\right)$, suppose that the possible health outcomes $(\bar{H}, \underline{H})$ and income $(\bar{Y}, \underline{Y})$ are both above the reference points $-H_{0}, Y_{0} . \bar{H}>\underline{H}>H_{0} ; \bar{Y}>\underline{Y}>Y_{0}$. For a given infestation level, S, the more risk averse person would spray more pesticide if he maximizes utility in the monetary domain to increase $\overline{p_{Y}} \cdot{ }^{24}$ However, the optimal overspray would be offset if the (dis)utility in the health domain from overspraying is taken into account. The overuse of pesticides caused by pesticide poisoning can results in higher $\underline{p_{H}}$, probability of a bad outcome, and thus amore risk averse person would spray less. Thus the optimal pesticide use would depend on the relative marginal utility of gain

\footnotetext{
${ }^{23} \mathrm{~S}$ can be any event that can be resulting in lower yield production, such as the probability of getting ineffective $\mathrm{Bt}$ seeds.

${ }^{24}$ Mathematically, it does not matter whether the perception of pest infestation is caused by the resistance of cotton bollworm or the rise of the mirids. We should find that a more risk averse person sprays more, holding the realized pest attack constant.
} 
in income, $\frac{d U_{Y}}{d x^{p}}$, and the marginal (dis)utility from loss in health due to the overspray of pesticide $\frac{d U_{H}}{d x^{p}}$.

For the relationship between loss aversion and optimal pesticide use, it would depend on whether $\bar{H}, \underline{H}, \bar{Y}, \underline{Y}$ are above $H_{0}, Y_{0}$. Suppose both $\bar{Y}, \underline{Y}$ are considered a gain, while health can be either a gain or a loss, $\bar{Y}>\underline{Y}>Y_{0}$ and $\bar{H}>H_{0}>\underline{H}$, then loss aversion in the monetary domain would not affect the optimal amount of pesticide use since $\underline{Y}$ is in the gain domain, i.e. above the reference point $Y_{0}$. However, in the health domain, the loss aversion amplifies the disutility of the bad health outcome $\underline{H}$. Hence, one would spray less pesticide to reduce the likelihood of the bad health outcome: $\underline{p_{H}}$. Alternatively, if the reference point is the expected income so that income can be either a gain or a loss, i.e. $\bar{Y}>Y_{0}>\underline{Y}$, then the underspray due to loss aversion in the health domain could be offset by loss aversion in the monetary domain. Hence, the net effect will again depend on the relative marginal utilities.

Finally, the probability weighting parameter $\alpha$ determines how much one overweights small probabilities and underweights large probabilities. The smaller the alpha is, the more one overweights small probabilities and the further away subjective probability departs from the objective linear probability. One might overweight the small probability event, such as severe pesticide infestation, ${ }^{25}$ and thus overspray pesticide. In the health domain, depending on whether one would consider the probability of being poisoned by pesticide to be a large (small) probability, the farmer could underweight (overweight) it, and thus use pesticide more (less) liberally. If the probability of being poisoned is a large probability, then higher $\alpha$ would imply more pesticide use; otherwise, the two forces offset and how pesticide use depends on $\alpha$ is

\footnotetext{
${ }^{25}$ By examining the average yield over time, we observe that extremely severe pest infestation takes place on average once in 10 years $(10 \%)$.
} 
ambiguous. In summary, the coefficient on $\sigma, \lambda, \alpha$ depends on the reference points in the utility curve. The optimal pesticide decision is a tradeoff between disutility of health loss and utility gain from higher income (yield).

In Section 5.3, we find that an increase in risk aversion may lead to an increase in pesticide use, but an increase in loss aversion lead to a decrease in pesticide use. The following example illustrates such a scenario. . Let us assume that there is linear probability weighting $(\alpha=1)$ in Equation 1 and $\bar{Y}>\underline{Y}>Y_{0}$ and $\bar{H}>H_{0}>\underline{H}$. We can then rewrite

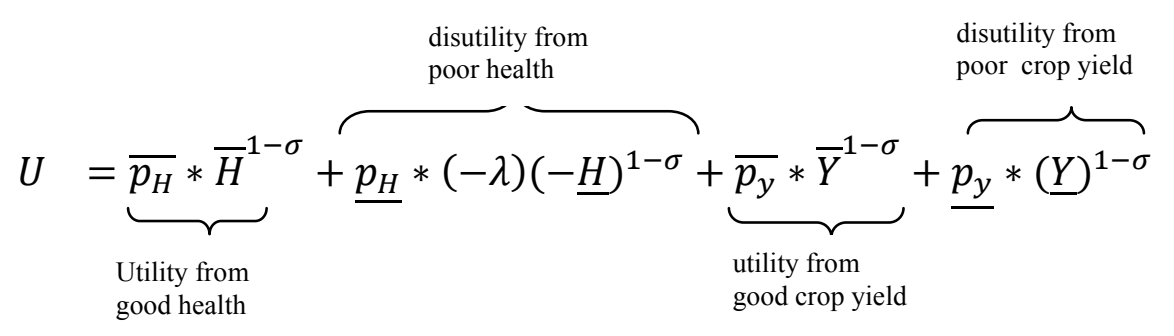

As we have previously discussed, $\frac{d \overline{p_{H}}}{d x^{p}}<0, \frac{d \underline{p_{H}}}{d x^{p}}>0, \frac{d \overline{p_{y}}}{d x^{p}}>0$ and $\frac{d \underline{p_{y}}}{d x^{p}}<0$. The optimal amount of pesticide $\left(x^{p *}\right)$ is a function of $(\sigma, \lambda)$. With this setting, when $\lambda$ increases, it would only increase the disutility from pesticide poisoning, but does not affect any other aspects. Therefore, $\left(x^{p *}\right)$ would decrease with an increasing $\lambda .^{26}$

Suppose $V(\sigma, \lambda)=U\left(x^{p *}(\sigma, \lambda)\right)$, applying the envelope theorem, we would have $\frac{d V}{d \lambda}=\frac{\partial U}{\partial x^{p *}} \cdot \frac{\partial x^{p *}}{\partial \lambda}$ and $\frac{d V}{d \sigma}=\frac{\partial U}{\partial x^{p *}} \cdot \frac{\partial x^{p *}}{\partial \sigma}$. One may rewrite this as $\frac{\partial x^{p *}}{\partial \sigma}=\frac{d V}{d \sigma} / \frac{\partial U}{\partial x^{p *}}$ and $\frac{\partial x^{p *}}{\partial \lambda}=\frac{d V}{d \lambda} / \frac{\partial U}{\partial x^{p *}}$.

$$
\begin{gathered}
\frac{d V}{d \sigma}=\frac{d U}{d \sigma} \mid x^{p}=x^{p *}=\overline{p_{H}}\left(x^{p *}\right) \cdot(-1) \cdot \bar{H}^{1-\sigma} \cdot \ln (\bar{H})+\underline{p_{H}} \cdot(\lambda)(-\underline{H})^{1-\sigma} \ln (-\underline{H}) \\
+\overline{p_{Y}}\left(x^{p *}\right) \cdot(-1) \cdot \bar{Y}^{1-\sigma} \cdot \ln (\bar{Y})+\underline{p_{Y}} *(-1) \cdot(\underline{Y})^{1-\sigma} \cdot \ln (\underline{Y})
\end{gathered}
$$

From the derivation in the online appendix, we find that $\frac{\partial U}{\partial x^{p *}}>0$, Thus if $\frac{\partial x^{p *}}{\partial \sigma}>0, \frac{d V}{d \sigma}>0$.

\footnotetext{
${ }^{26}$ In the online appendix available on the author's website, we show the derivation of this negative relationship.
} 
For example, if $e>\bar{Y}>\underline{Y}>0$ and $|\underline{H}|>e>\bar{H}>0, \frac{d V}{d \sigma}>0$, we would have our empirical results - an increase in risk aversion can lead to an increase in pesticide use, while an increase in loss aversion can lead to a decrease in pesticide use. In the next section, we set up the econometric framework to empirically test the relationship between farmers' risk preferences and their pesticide use.

\section{Econometric Framework and Regression Results for Pesticide Use}

\subsection{Basic Framework}

We first replicate Huang, et al.'s (2002b) results without the risk preference parameters, so we estimate the following equation by ordinary least square (OLS):

$$
y_{i j v}=\delta_{o}+\delta_{1} B t_{i j v}+\delta_{2}(B t \exp )_{i j v}+\gamma X_{i j v}{ }^{\prime}+\mu_{v}+\varepsilon_{i j v},
$$

where $i$ denotes individual, $j$ denotes plot, and $v$ denotes village; $y_{i j v}$ is the amount of pesticides (in $\mathrm{kg}$ per hectare) sprayed for individual $i$, on plot $j$, in village $v ; B t_{i j v}$ equals one if Bt cotton is planted and zero otherwise; (Btexp) $)_{i j v}$ is the number of years that farmer $i$ has planted Bt cotton interacted with the use of $\mathrm{Bt}$ cotton; $X^{\prime}{ }_{i j v}$ is a vector of individual or plot characteristics, such as plot size, age, and years of education; and $\mu_{v}$ is a village fixed effect. The main coefficients of interest are $\delta_{1}$ and $\delta_{2} . \delta_{l}$ represents the effectiveness of Bt cotton in reducing pesticide use 10 years after Bt cotton's commercialization. The significance of $\delta_{2}$ is more complicated. There are two opposing factors that can affect this coefficient. First, if the cotton bollworm builds up a resistance to Bt toxin, more pesticides would need to be used over time and $\delta_{2}$ should be positive. In contrast, if farmers become more aware of the benefits of using Bt cotton as they have more experience with planting Bt cotton, $\delta_{2}$ should be negative.

[Insert Table 4 About Here]

Column 1 of Table 4 shows the results from the estimation of equation (3). We find that 
more educated farmers use significantly less pesticides. For every additional year of education a farmer has undergone, he reduces pesticide use by $0.73 \mathrm{~kg}$ per hectare, which is equivalent to $2.7 \%$ of total pesticide use (among Bt cotton farmers). In other words, farmers who finish elementary school use $16 \%$ less pesticides than farmers with no education. The coefficient on plot size is negative and significant, which could be a sign of economies of scale. In addition, farmers use less pesticide when the price of pesticides is high. The main coefficient of interest $(\delta$ 1) indicates that the cultivation of Bt cotton reduces pesticide use dramatically. All else equal, the average Bt cotton farmer reduces pesticide use by $19.5 \mathrm{~kg}$ per hectare on his Bt cotton plot compared with his traditional cotton plot. The coefficient on the interaction term $\left(\delta_{2}\right)$ is positive, but it is not statistically significant from zero, which may simply mean that the two aforementioned factors cancel each other out. Overall, we conclude that even a decade after the commercialization of $\mathrm{Bt}$ cotton, cotton farmers still use significantly less pesticides on their $\mathrm{Bt}$ cotton plots than on their traditional cotton plots. In all regressions that follow, the standard errors are corrected for heteroskedasticity at the individual level.

Next, we include the elicited measure of risk preferences in the rest of the estimation. We can rewrite equation (3) as:

$$
y_{i j v}=\delta_{o}+\delta_{1} B t_{i j v}+\delta_{2}(B t \exp )_{i j v}+\delta_{3} \sigma_{i}+\delta_{4} \lambda_{i}+\delta_{5} \alpha_{i}+\gamma X_{i j v}{ }^{\prime}+\mu_{v}+\varepsilon_{i j v}
$$

where $\sigma$ is the coefficient of risk aversion, $\lambda$ is a measure of loss aversion, and $\alpha$ is a measure of nonlinear probability weighting. A higher $\sigma$ or $\lambda$ implies greater risk or loss aversion, respectively. $\alpha<1(\alpha>1)$ implies the overweighting (underweighting) of small probability events. The results of estimating equation (4) are shown in Columns 2 and 3 of Table 4 . The coefficient on $\sigma$ of 7.244 indicates that if a farmer is more risk averse than the average farmer by one standard deviation, he will use $2.39 \mathrm{~kg}$ per hectare $(9 \%)$ more pesticides than the average 
farmer. There could be several reasons why we find a positive coefficient on the risk aversion parameter. One such possible reason is that farmers worry about severe bollworm pest attack, which is exacerbated by the fact that lower quality Bt cotton seeds are rampant in the seed market. Not knowing whether the Bt cotton seed is effective nor how severe the bollworm problem will be, the more risk-averse farmers will likely spray greater quantities of pesticides.

The coefficient on $\lambda$ of -0.502 implies that if a farmer is one standard deviation more loss averse than the average farmer, he will use $1.96 \mathrm{~kg}$ per hectare $(7 \%)$ less pesticide than the average farmer. The negative sign on this coefficient would be consistent with the results from the example in Section 4.2, where the outcomes in monetary domains are above the reference point $\bar{Y}>\underline{Y}>Y_{0}$ and $\bar{H}>H_{0}>\underline{H}$, thus the coefficient on loss aversion parameter reflects the disutility in the health domain. We will further investigate this possibility in Section 5.3. As illustrated in Section 4.2, there is no clear prediction for the coefficient on a nonlinear probability weighting parameter. We find nonlinear probability weighting to be positive and marginally statistically significant.

Negative and significant coefficients on education in all of the above estimations suggest that less educated farmers did not benefit as much from the introduction of Bt cotton. In fact, what this education variable captures is the farmers' knowledge of how to properly use Bt cotton and effective pest management. While it may be too late to provide formal schooling to adult farmers, one policy intervention to help educate farmers is training sessions. We find the coefficient on training to be large with a reduction of nearly one standard deviation of pesticide use, and it is marginally insignificant at $11 \%$. The Chinese government has already provided such services, but the utilization rate of these services is far below $100 \%$; in our sample, merely $35 \%$ of farmers had ever attended a Bt cotton training session. These training sessions are 
usually provided by agricultural extension services or seed companies in each village. There is at least one farmer in each village who reported attending a training session in each year, so the low participation rate is not due to a lack of availability of training sessions at the village level.

The findings here suggest that education and agricultural training could help farmers reduce their pesticide use. The coefficients on training presented in this section could suffer from upward bias due to an omitted variable. For example, it is possible that the more motivated farmers are more likely to attend training sessions and could be more knowledgeable about $\mathrm{Bt}$ cotton even in the absence of receiving training sessions. Unfortunately, we cannot investigate further due to the limitation of the dataset.

\subsection{Pest Severity}

One covariate that is missing from the above estimation is pest severity. Lu et al.'s (2010) paper published in Science concludes that in an area where the Bt cotton planting proportion is high, the number of mirid bugs found in the area is high. Given that almost all of the plots in our survey are of Bt cotton, it is safe to assume that the proportion of Bt cotton planting in the surveyed area is close to $100 \%$. Moreover, the size of the mirid population has been found to fluctuate with rainfall and temperature (Ting, 1963; Wu et al., 2002; Wang et al. 2009). If we take Lu et al.'s finding seriously, the level of mirid infestation for individual $i$ in village $v, M_{i v}$, is a function of Bt cotton plant portion in the village, rainfall in the village, temperature in the village, and the error term, $\varepsilon_{i}$. Therefore, once we control for village fixed effect in our regression specification, we are left with the error terms, $\varepsilon_{i}$. As long as $\varepsilon_{i}$ is orthogonal to our measure of risk preference, then the coefficients on risk preference, which is the main focus of the paper, would not be biased even if we do not control for $\varepsilon_{i}$. Alternatively, we also try to collect farmers' perception of pest severity using the following questions: 
What do you think your potential yield loss will be if you do not spray any pesticide for controlling bollworm? (0-100 percent)

What do you think your potential yield loss will be if you do not spray any pesticide for controlling mirids? ${ }^{27}$ (0-100 percent)

We can use the answers to these questions as proxies for pest severity with higher values indicating a more severe pest problem. ${ }^{28}$ These measures of pest severity are extremely subjective. The results including these measures are presented in Column 4 of Table 4 . Our main coefficients of interest — risk preferences — remain robust. Coefficients on pest severity are positive and insignificant. One other result worth noting is that the magnitude of the coefficient on education is smaller, but it remains positive and significant at the $10 \%$ level, which implies that education is correlated with farmers' perceptions of pest severity. ${ }^{29,30}$ We also try alternative specifications including regression with only mirids severity, with bollworms severity only, with the mean perceived infestations of bollworms and mirids and regression with an interaction term between risk preferences and severity. The coefficients of risk preferences are quite constant. The results for these alternative specifications are available as an Online Appendix. Given the subjectivities of these pest measures, Column 3 of Table 4 would be our preferred specification throughout the paper.

\subsection{Other Hypothesis}

As discussed in Section 2, two of the possible reasons why farmers use more pesticide are:

\footnotetext{
${ }^{27}$ Mirids are reported by Wang et al. (2006) as being the most serious secondary pest to Chinese Bt cotton farmers.

${ }^{28}$ The same methodology is also used by Huang, et al. (2002b). We try to correlate each of the pest severity measures with the individual risk preference. We find risk preference cannot predict pest severity, and the correlation between them is low.

${ }^{29}$ In a separate regression not reported in the current paper, when we regress the yield loss on levels of education, controlling for village fixed effects, the coefficient on education is negative and significant at the $1 \%$ level. Thus, higher levels of education are associated with lower perceptions of yield loss.

${ }^{30}$ Across columns, the numbers of observations have changed due to missing data. We also try to use one consistent sample set from Column 4 with specifications from Columns 1 to 3 , and we find little difference in the regressions results. This table is available in the Online Appendix.
} 
the wide variation in the quality of Bt cotton seeds and the false information from agricultural extension agents. We will explore these two hypotheses in this section.

First, Figure 1 shows the distribution of the cost of Bt cotton seeds from 2 to 200 Yuan per kg. Figure 2 is a histogram of the distribution of $930 \mathrm{Bt}$ cotton plots according to the source of the seed, cross referenced with the average seed price for each source. ${ }^{31}$ The cheapest seeds are those produced through on-farm propagation, also known as the saved seeds. We asked farmers if they knew whether the saved seeds were of lower, the same, or better quality than the first generation Bt cotton seeds. Thirty percent of farmers reported that they believed saved seeds to be of the same quality, $7 \%$ reported that they did not know, and $63 \%$ correctly answered that the saved seeds are of inferior quality. The misperception of the quality of Bt cotton seeds may explain why a full $25 \%$ of seeds for Bt cotton plots are attained through on-farm propagation.

[Insert Figure 1 About Here]

[Insert Figure 2 About Here]

To investigate whether the source or the price of Bt cotton seeds is a determinant of pesticide use, we restricted the sample to only Bt cotton plots. While pesticide use could be an indicator of Bt cotton seed quality, it is not a good indicator for traditional cotton seed quality. The quality of conventional cotton is determined by its yield performance, which is not captured in our estimation.

\section{[Insert Table 5 About Here]}

The regressor of interest is the seed price, which is presented in Column 1 of Table 5. The coefficient on seed price is not statistically different from zero. The finding here complements

\footnotetext{
${ }^{31}$ For the saved seeds and the seeds exchanged by neighbors, we asked farmers for an estimate of the market value of the seeds.
} 
Pemsl's (2006) finding that the more expensive Bt cotton seeds are not significantly more pest resistant than the cheaper Bt cotton seeds. In column 2, we include a series of dummy variables for the source of the seeds, for which the default source is "others." None of the source dummies are statistically different from zero. In an alternative regression specification for which the results are not presented in the current paper, we include an interaction term between source indicators and the price of the seeds, and once again, none of the coefficients are statistically different from zero. This suggests that the quality of Bt seeds may not be dictated by the price and the source.

We then examine farmers' reporting of source of information. In the survey we ask "how do you determine how much pesticide you should spray?" (Rank top 3 in order). The tabulated result is presented in Figure 3. Only 5\% of farmers indicate that they rely on information from agricultural extension agents as their number 1 source of information when deciding how much pesticide to spray. A dummy variable indicating whether an individual lists information from agricultural extension agent as the number 1 source of information in determining pesticide use is included in the regression and the results are presented in Table 6. We find that farmers who follow extension agents' advice reduce their pesticide use by $6.39 \mathrm{~kg} / \mathrm{ha}$. We also create another dummy for indicating whether agricultural extension agent is in the top 3 sources of information, but the coefficient on the dummy is no longer significant. We find no evidence that getting information from extension agent is correlated with higher pesticide use.

[Insert Figure 3 About Here]

[Insert Table 6 About Here]

\subsection{Robustness Check}

One might worry that our results could be driven by a few outliers, so we use natural log of 
pesticide use as a dependent variable and the results are presented in Column 1 of Table 7. In Column 2, we report regression results using an alternative measure of pesticide, total pesticide expenditure per hectare. Other than Table 6 , the unit of observation in the regressions has been at the plot level. The advantage of using plot level information is that we have detailed information about the seed used on each plot. It is common that within the same household, seeds used on various plots are from a variety of sources. Therefore, in order to investigate the impact of seed (such as sources of the seeds or the Bt characteristics of the seeds), the regression would have to be at the plot level. However, one might suspect, the plot level pesticide expenditure could suffer from measurement error as it is more difficult for farmers to estimate the pesticide expenditure by plot. As a robustness check, we examine the relationship between risk preferences and pesticide use at the household level. We keep only plots with Bt cotton. The dependent variable is also pesticide use (kilogram per hectare). The results are presented in Column 3. Coefficients on risk preferences are slightly smaller compared to Table 4, but they remain significant at the $10 \%$ level.

\section{[Insert Table 7 About Here]}

So far we have imposed a strong function form on the utility function when we impute the risk preference parameters. As a robustness check, we will relax the utility function form and simply divide farmers into 18 groups depending on their three switching points in the lottery game (see Figure 3). For instance, group 1 includes the farmers who switched from lottery A to lottery B before Row 6 in both Series 1 and 2 and switched before Row 4 in Series 3 (thus group 1 should contain the most risk-seeking and least loss-averse individuals). Group 18 includes those farmers who switched from lottery A to lottery B after Row 11 in both Series 1 and 2 and switched after Row 4 in Series 3 (thus group 18 should be the most risk averse and loss averse 
group). In a regression, instead of using the three risk preference parameters as the specification in Table 4 Column 4, we include the group dummies. ${ }^{32}$ An $F$-test rejects the null hypothesis that these group dummies jointly equal to zero at the $5 \%$ level. Even without imposing the utility functional form, we know that the TCN field experiment can predict pesticide use. We are inclined to believe that the field experiment design captures individual heterogeneity in risk preferences and the functional form helps to ease the interpretation.

[Insert Figure 4 About Here]

\subsection{Loss Aversion}

Throughout the analysis, the coefficients on loss aversion are always negative and significant. Following the discussion in Section 4.2, we know that optimal pesticide decision making is a combination of tradeoff between disutility of health loss and utility gain from higher income (yield). The negative coefficient suggests that the disutility from health loss dominates in the loss aversion domain. ${ }^{33}$

To further examine this claim, we divide farmers into 4 groups based on their coefficient of loss aversion, group 1 being the least loss averse (1st quartile) and group 4 being the most loss averse (fourth quartile). Regression results including these dummies are reported in Column 1 of Table $8 .^{34}$ The missing dummy is for those who are in the first quartile, the least loss averse farmers (lambda $<=0.83$ ). While the dummies are not statistically significant, the negative coefficients on group dummies indicate that all other groups (more loss averse) would spray less

\footnotetext{
${ }^{32}$ Since coefficients on group dummies cannot be interpreted meaningfully, the estimates are not reported for brevity.

${ }^{33}$ There could be two interpretations why health loss dominates over monetary loss. One is that the reference point for monetary outcome is set low enough $\left(\bar{Y}>\underline{Y}>Y_{0}\right)$, therefore loss aversion never plays a role in the monetary domain. The second is that disutility from the income loss is much smaller compared to disutility for health loss, $\mathrm{U}(\underline{Y})>U(\underline{H})$.

${ }^{34}$ In this table we exclude those individuals who were just pesticide poisoned in 2006. Our measure of pesticide use is also from 2006, so presumably those who were just poisoned in 2006 did not have a chance to adjust their pesticide use in 2006 season yet.
} 
relative to the least loss averse group. This is consistent with our hypothesis. With the data available, we further examine whether farmers who have experienced severe pesticide poisoning would behave differently from those who have not. Presumably, the farmers who have had firsthand experience with pesticide poisoning would be more loss averse in the health domain and those with more severe pesticide poisoning episodes (as proxied by total medical cost incurred due to pesticide poisoning) would be more conscious about loss of health, and thereby reduce pesticide use more. In Column 2, we present results with a set of loss aversion quartile dummies and the interaction terms between cost of pesticide poisoning and the quartile dummies. First, the negative coefficients on the interaction terms imply that those who are more severely poisoned would spray less. Second, most of the negative results are driven by those who are in the fourth quartile, the most loss averse. We find that for those individuals who are the most loss averse (in the fourth quartile), for every 100 Yuan of pesticide poisoning cost, they would reduce their pesticide use by $1.826 \mathrm{~kg} / \mathrm{Ha}(6 \%)$, relative to those who are least loss averse. In summary, we provide some suggestive evidence that loss aversion could exist in the health domain.

$$
\text { [Insert Table } 8 \text { About Here] }
$$

\section{Conclusion}

We investigate the determinants of pesticide use among Chinese Bt cotton farmers. Controlling for village fixed effects, our main findings are that the more risk-averse farmers use greater quantities of pesticides, while the more loss-averse farmers use lesser quantities of pesticides. The findings of this study have important policy implications. They suggest that farmers may not benefit as much from new technology as policy makers and scientists would hope. Simply achieving a Bt cotton adoption rate of $100 \%$ does not guarantee that farmers will know how to fully capitalize on this new technology. In order to ensure that farmers reap all the 
benefits of modern science, formal education and continuing education, such as training sessions provided by the government, are essential. Given that more risk averse farmers adopt Bt cotton later and continue to use excessive pesticide even after adopting Bt cotton, the government could offer crop insurance, which helps mitigate the potential agricultural production risk.

Several hypotheses have been put forth by other researchers to explain the cause of overuse of pesticide in China, including problems with counterfeit Bt seed, false information from extension agents and the rising of secondary pests. In our analysis, once we control for village fixed effects, we find no evidence that these hypotheses can explain the difference in pesticide use by farmers within the same villages. Another interesting result from our paper is that we find suggestive evidence that loss aversion could exist in the health domain. While health has long been considered a part of the utility function since Grossman's seminal work (1972), very few papers have extended the utility function beyond the expected utility functional form to incorporate health. Given the data limitation, it is beyond the scope of this paper to fully test whether loss aversion exists in health domain. It is a topic of interest for future research. 


\section{References}

Ackerberg, D., \& Botticini, M. (2002). Endogenous matching and the empirical determinants of contract form. Journal of Political Economy, 110(3), pp. 564-591.

Altieri, M. A. (2004). Genetic engineering in agriculture : The myths, environmental risks, and alternatives (2nd ed.). Oakland, Calif.: Food First Books/Institute for Food and Development Policy.

Anderson, L., \& Mellor, J. (2009). Are risk preferences stable? comparing an experimental measure with a validated survey-based measure. Journal of Risk and Uncertainty, 39(2), 137-160.

Antle, J. M. (1988). Pesticide policy, production risk and producer welfare: An econometric approach to applied welfare economics. Johns Hopkins University Press,

Barberis, N., Huang, M., \& Santos, T. (2001). Prospect theory and asset prices. Quarterly Journal of Economics, 116(1), 1-53.

Bardsley, P., \& Harris, M. (1987). An approach to the econometric estimation of attitudes to risk in agriculture. Australian Journal of Agricultural Economics, 31(02)

Barseghyan, L., Prince, J., \& Teitelbaum, J. C. (2011). Are risk preferences stable across contexts? evidence from insurance data. American Economic Review, 101(2), 591-631.

Barwale, R. B., Gadwal, V. R., Zehr, U., \& Zehr, B. (2004). Prospects for bt cotton technology in india. AgbioForum, 7(1\&2), 22-26.

Bellemare, M. F., \& Brown, Z. S. (2009). On the (mis)use of wealth as a proxy for risk aversion. American Journal of Agricultural Economics, 92(1), 273-282.

Bennett, R. M., Buthelezi, T. J., Ismael, Y., \& Morse, S. (2003). Bt cotton, pesticides, labour and health: A case study of smallholder farmers in the makhathini flats, republic of south africa. Outlook on Agriculture, 32(2), 123-128.

Bentley, J. W., \& G., T. (March 1999). Bibliography: Farmer knowledge and management of crop disease. Agriculture and Human Values, 16, 75-81(7).

Binswanger, H. P. (1980). Attitudes toward risk: Experimental measurement in rural india. American Journal of Agricultural Economics, 62(3), 395-407.

Binswanger, H. P. (1981). Attitudes toward risk: Theoretical implications of an experiment in rural india. The Economic Journal, 91(364), 867-890. 
Bleichrodt, H., \& Pinto, J. L. (2002). Loss aversion and scale compatibility in two-attribute trade-offs. Journal of Mathematical Psychology, 46(3), 315-337.

Bleichrodt, H., Pinto, J. L., \& Wakker, P. P. (2001). Making descriptive use of prospect theory to improve the prescriptive use of expected utility. Management Science, 47(11), 1498-1514.

Bond, G., \& Wonder, B. (1980). Risk attitudes amongst australian farmers. Australian Journal of Agricultural Economics, 24, 16-34.

Camerer, C., \& Kunreuther, H. (1989). Decision processes for low probability events: Policy implications. Journal of Policy Analysis and Management, 8(4), 565-592.

Campbell, R. A., \& Kräussl, R. (2007). Revisiting the home bias puzzle: Downside equity risk. Journal of International Money and Finance, 26(7), 1239-1260.

Chavas, J., \& Holt, M. T. (1996). Economic behavior under uncertainty: A joint analysis of risk preferences and technology. The Review of Economics and Statistics, 78(2), 329-335.

Conko, G., \& Prakash, C. S. (December 13, 2004, Can GM crops play a role in developing countries? Biotechnology and Developing Countries: The Potential and the Challenge, 2004

Dillon, J. L., \& Scandizzo, P. L. (1978). Risk attitudes of subsistence farmers in northeast brazil: A sampling approach. American Journal of Agricultural Economics, 60(3), 425-435.

Dohmen, T., Falk, A., Huffman, D., Sunde, U., Schupp, J., \& Wagner, G. (2005). Individual risk attitudes: New evidence from a large, representative, experimentally-validated survey No. 1730)Institute for the Study of Labor (IZA).

Dubois, P. (2002). Moral hazard, land fertility and sharecropping in a rural area of the philippines. Journal of Development Economics, 68(1), 35-64.

Feder, G. (1980). Farm size, risk aversion and the adoption of new technology under uncertainty. Oxford Economic Papers, 32(2), 263-283.

Fehr, E., \& Goette, L. (2007). Do workers work more if wages are high? evidence from a randomized field experiment. American Economic Review, 97(1), 298-317.

Foster, A. D., \& Rosenzweig, M. R. (1995). Learning by doing and learning from others: Human capital and technical change in agriculture. The Journal of Political Economy, 103(6), 11761209.

Fukunaga, K., \& Huffman, W. E. The role of risk and transaction costs in contract design: Evidence from farmland lease contracts in U.S. agriculture. American Journal of Agricultural Economics, Vol.91, no.1, Pp.237-249, February 2009,

Fung, P. L. P. (2005). No soft landing. Oxfam Briefing Paper, 
Gonzalez, R., \& Wu, G. (1999). On the shape of the probability weighting function, Cognitive Psychology, 38(1), 129-166.

Grossman, M. (1972). On the concept of health capital and the demand for health. Journal of Political Economy, 80(2), pp. 223-255.

Harrison, G. W., \& List, J. A. (December 2004). Field experiments. Journal of Economic Literature, 42, 1009-1055(47).

Holt, C. A., \& Laury, S. K. (2002). Risk aversion and incentive effects. The American Economic Review, 92(5), 1644-1655.

Huang, J., Hu, R., Rozelle, S., Qiao, F., \& Pray, C. E. (2002). Transgenic varieties and productivity of smallholder cotton farmers in china. The Australian Journal of Agricultural and Resource Economics, 46(3), 367-388.

Huang, J., Rozelle, S., Pray, C., \& Wang, Q. (2002). Plant biotechnology in china. Science, 295(5555), 674-676.

Jovanovic, B., \& Nyarko, Y. (1996). Learning by doing and the choice of technology. Econometrica, 64(6), pp. 1299-1310.

Just, R. E. (2008). Distinguishing preference and perceptions for meaningful policy analysis. Orlando, FLorida. , presidential address at the Annual Meetings of the American Agricultural Economics Association

Just, D. R., \& Lybbert, T. (2009). Risk averters that love risk? marginal risk aversion in comparison to a reference gamble. American Journal of Agricultural Economics, 91(3), 612.

Kahneman, D., \& Tversky, A. (1979). Prospect theory: An analysis of decision under risk. Econometrica, 47(2), 263-291.

Laffont, J., \& Matoussi, M. S. (1995). Moral hazard, financial constraints and sharecropping in el oulja. Review of Economic Studies, 62(3), 381-399.

Lichtenberg, E., \& Zilberman, D. (1986). The econometrics of damage control: Why specification matters. American Journal of Agricultural Economics, 68(2), pp. 261-273.

Lipton, M. (2001). Reviving global poverty reduction: What role for genetically modified plants?, Journal of International Development, 13(7), 823-846.

List, J. A. (2003). Does market experience eliminate market anomalies? Q.J.Econ., 118(1), 41.

Liu, E. (2011). Time to change what to sow: Risk preferences and technology adoption decisions of cotton farmers in china. Unpublished manuscript. 
Loppacher, L., \& Kerr, W. (2004). China's regulation of biotechnology: Does it conform to the WTO?, Estey Centre for Law and Economics in International Trade, Mimeo,

Lu, Y., Wu, K., Jiang, Y., Xia, B., Li, P., Feng, H., et al. (2010). Mirid bug outbreaks in multiple crops correlated with wide-scale adoption of bt cotton in china. Science, 328(5982), 11511154.

The characteristics of bt cotton and the integrated pest management.(March 20, 2003, Louyang Agricultural News,

Morse, S., Bennett, R. M., \& Ismael, Y. (2005). Genetically modified insect resistance in cotton: Some farm level economic impacts in india. Crop Protection, 24(5), 433-440.

Moscardi, E., \& Janvry, A. d. (1977). Attitudes toward risk among peasants: An econometric approach. Am.J.Agric.Econ., 59(4), 710-716.

Moschini, G., \& Hennessy, D. A. (2001). Uncertainty, risk aversion, and risk management for agricultural producers. In B. L. Gardner, \& G. C. Rausser (Eds.), Handbook of agricultural economics\}; handbook of agricultural economics (pp. 88-153) Elsevier.

Officer, R. R., \& Halter, A. N. (1968). Utility analysis in a practical setting. American Journal of Agricultural Economics, 50(2), 257.

Pemsl, D. (2006). Economics of agricultural biotechnology in crop protection in developing countries - the case of bt-cotton in shandong province, china. Hannover: Pesticide Policy Project.

Pemsl, D., \& Waibel, H. (2005). Why do some bt-cotton farmers in china continue to use high levels of pesticides?, International Journal of Agricultural Sustainability, 3(1), 44-56.

Piao, Y., Yang, P., \& Guo, R. Status of bt cotton and its impact on cotton production in china. Bangkok, Thailand. 2-3.

Polkovnichenko, V. (2005). Household portfolio diversification: A case for rank-dependent preferences. Review of Financial Studies, 18(4), 1467-1502.

Pray, C. E., Huang, J., Hu, R., \& Rozelle, S. (2002a). Five years of bt cotton in china - the benefits continue. Blackwell Publishing Limited.

Pray, C. E., Huang, J., Hu, R., Wang, Q., Ramaswami, B., \& Bengali, P. (2006). Benefits and costs of biosafety regulation in india and china. In R. E. Just, J. M. Alston \& D. Zilberman (Eds.), Regulating agricultural biotechnology: Economics and policy (pp. 481-508) Springer US.

Pray, C., Ma, D., Huang, J., \& Qiao, F. (2001). Impact of bt cotton in china. World Development, $29(5), 813-825$. 
Prelec, D. (1998). The probability weighting function. Econometrica, , 497.

Qaim, M., \& De Janvry, A. (2005). Bt cotton and pesticide use in argentina: Economic and environmental effects. Environment and Development Economics, 10(2), 179-200.

Qaim, M., Subramanian, A., Naik, G., \& Zilberman, D. (2006). Adoption of bt cotton and impact variability: Insights from india. Review of Agricultural Economics, 28(1), 48-58.

Qaim, M., \& Zilberman, D. (2003). Yield effects of genetically modified crops in developing countries. Science, 299(5608), 900-902.

Rozelle, S., Huang, J., Lin, H., Hu, R., \& Pray, C. E. (2006). Eight years of bt cotton in farmer fields in china: Is the reduction of insecticide use sustainable?, FSI Stanford Publications Working Paper,

Ruttan, V. W. (2004). Controversy about agricultural technology lessons from the green revolution. International Journal of Biotechnology, 6(1), 43.

Saha, A., Shumway, C. R., \& Talpaz, H. (1994). Joint estimation of risk preference structure and technology using expo-power utility. American Journal of Agricultural Economics, 76(2), 173-184.

Samuelson, L. (2005). Economic theory and experimental economics. Journal of Economic Literature, 43(1), 65-107.

Schechter, L. (2007). Theft, gift-giving, and trustworthiness: Honesty is its own reward in rural paraguay. American Economic Review, 97(5), 1560-1582.

Shaw, K. L. (1996). An empirical analysis of risk aversion and income growth. Journal of Labor Economics, 14(4), 626-653.

Shi, G., \& Pray, C. (2011). Modeling agricultural innovation in a rapidly developing country: The case of chinese pesticide industry. Agricultural and Applied Economics Association Conference.

Tanaka, T., Camerer, C. F., \& Nguyen, Q. (2010). Risk and time preferences: Linking experimental and household survey data from vietnam. American Economic Review, 100(1), 557-571.

Ting, Y. Q. (1963). Studies on the ecological characteristics of cotton mirids. I. effect of temperature and humidity on the development and distribution of the pests. Acta Phytophylacica Sin., 2(3), 285.

Wang, Z. (2008). Essays on bt cotton. Unpublished Ph.D., The Center for Chinese Agricultural Policy, 
Wang, H., Hua, X., \& Mou, J. (1999). The integrated pest management of cotton bollworm. Beijing, China: China Agricultural Press.

Wang, S., Just, S., \& Pinstrup-Andersen, P. (2006). Tarnishing silver bullets: Bt technology adoption, bounded rationality and the outbreak of secondary pest infestations in china. American Agricultural Economics Association Annual Meeting, Long Beach, CA. July 22-26,

WANG, Z., LIN, H., HUANG, J., HU, R., Rozelle, S., \& Pray, C. (2009). Bt cotton in china: Are secondary insect infestations offsetting the benefits in farmer fields? Agricultural Sciences in China, 8(1), 83-90.

$\mathrm{Wu}, \mathrm{K}$. (2007). Monitoring and management strategy for helicoverpa armigera resistance to bt cotton in china. Journal of Invertebrate Pathology, 95(3), 220-223.

Wu, K., Li, W., Feng, H., \& Guo, Y. (2002). Seasonal abundance of the mirids, lygus lucorum and adelphocoris spp. (hemiptera: Miridae) on bt cotton in northern china. Crop Protection, 21(10), 997-1002.

Wu, K., Lu, Y., Feng, H., Jiang, Y., \& Zhao, J. (2008). Suppression of cotton bollworm in multiple crops in china in areas with bt Toxin Containing cotton. Science, 321(5896), 16761678 .

Xia, J., Cui, J., Ma, L., Dong, S., \& Cui, X. (1998). The role of transgenic bt cotton in integrated insect pest management. Acta Gossypii, (11), 57-64.

Yang, P., \& Jiang, R. (1995). Review of nation-wide IPM strategies for the control of cotton bollworm in 1994 and 1995. Progress report of IPM of cotton bollworm (). Beijing, China: China Agricultural Press.

Yang, P., Iles, M., Yan Su, \& Jolliffe, F. (2005). Farmers' knowledge, perceptions and practices in transgenic bt cotton in small producer systems in northern china. Crop Protection, 24(3), 229-239.

Young, D. L. (1979). Risk preferences of agricultural producers: Their use in extension and research. American Journal of Agricultural Economics, 61(5, Proceedings Issue), 1063-1070.

Zhu, E. (August 13, 2006). RE: Bt cotton E-mail to the author.

Zilberman, D., Ameden, H., \& Qaim, M. (2007). The impact of agricultural biotechnology on yields, risks, and biodiversity in low-income countries. The Journal of Development Studies, 43(1), 63-78. 

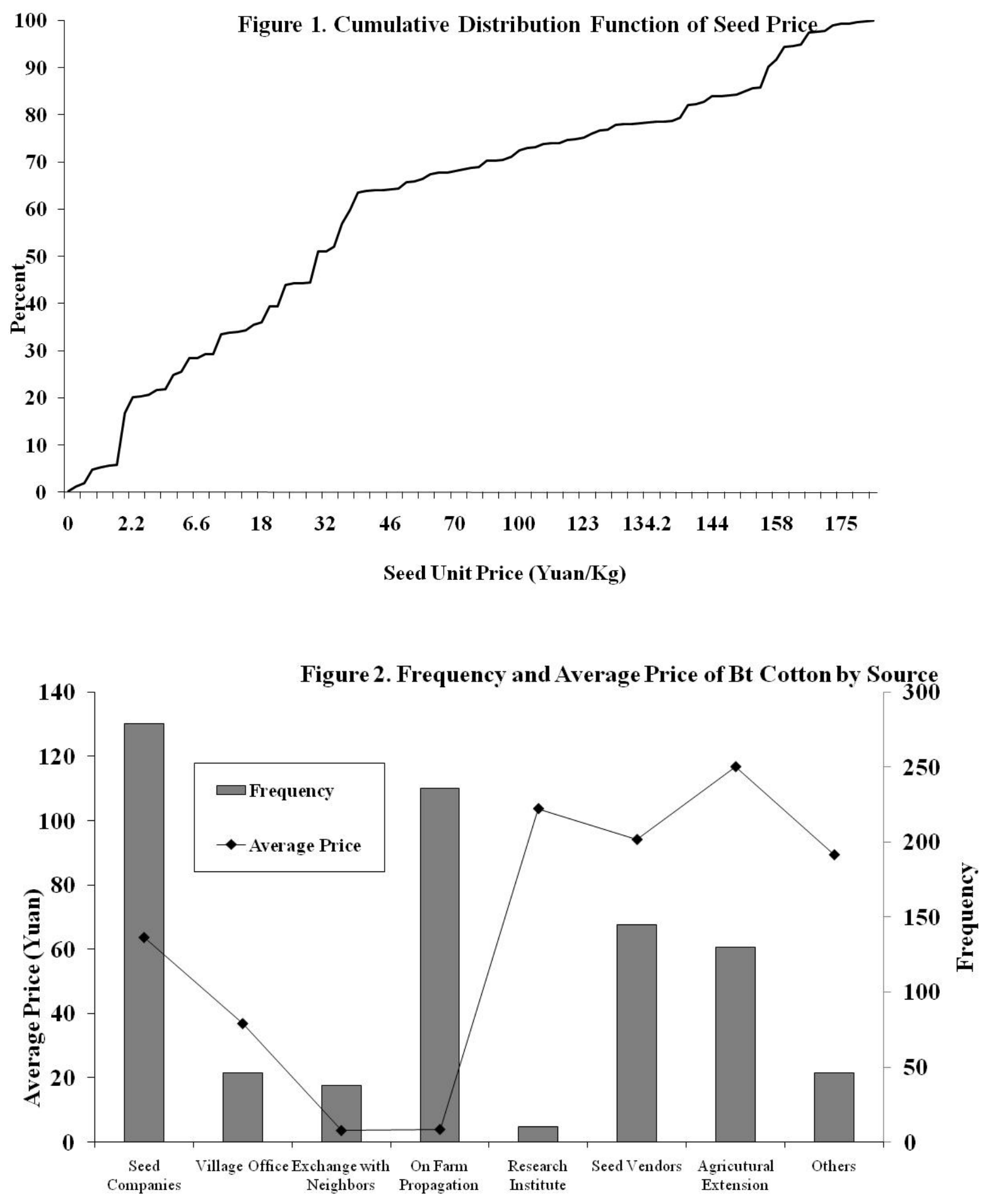

Source 
Figure 3. Breakdown of Top 3 Sources of Information for Amount of Pesticide Use

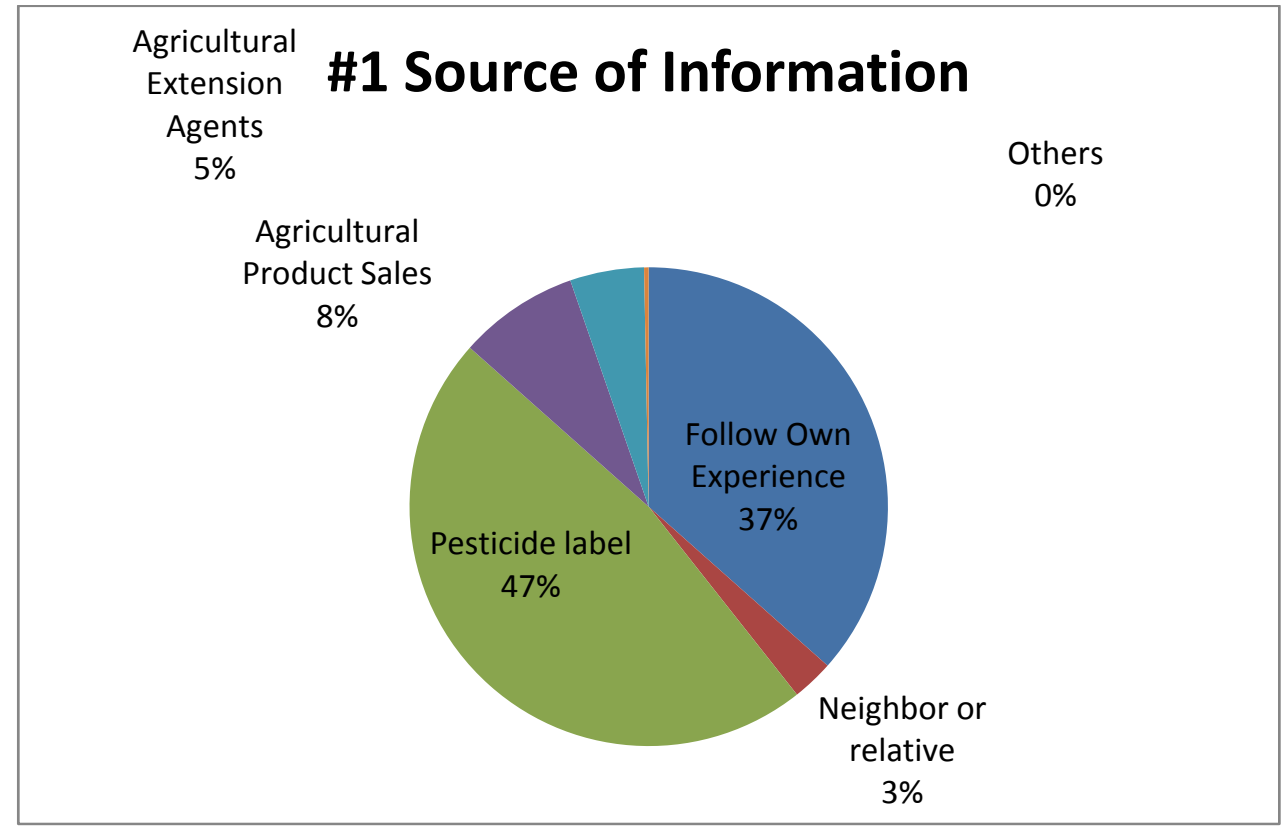

\section{Agricultural Extension Agents \\ \#2 Source of Information $3 \%$

Agricultural Product Sales $8 \%$

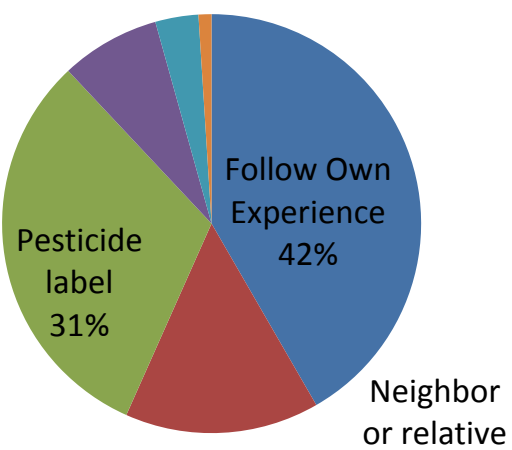
$15 \%$ 


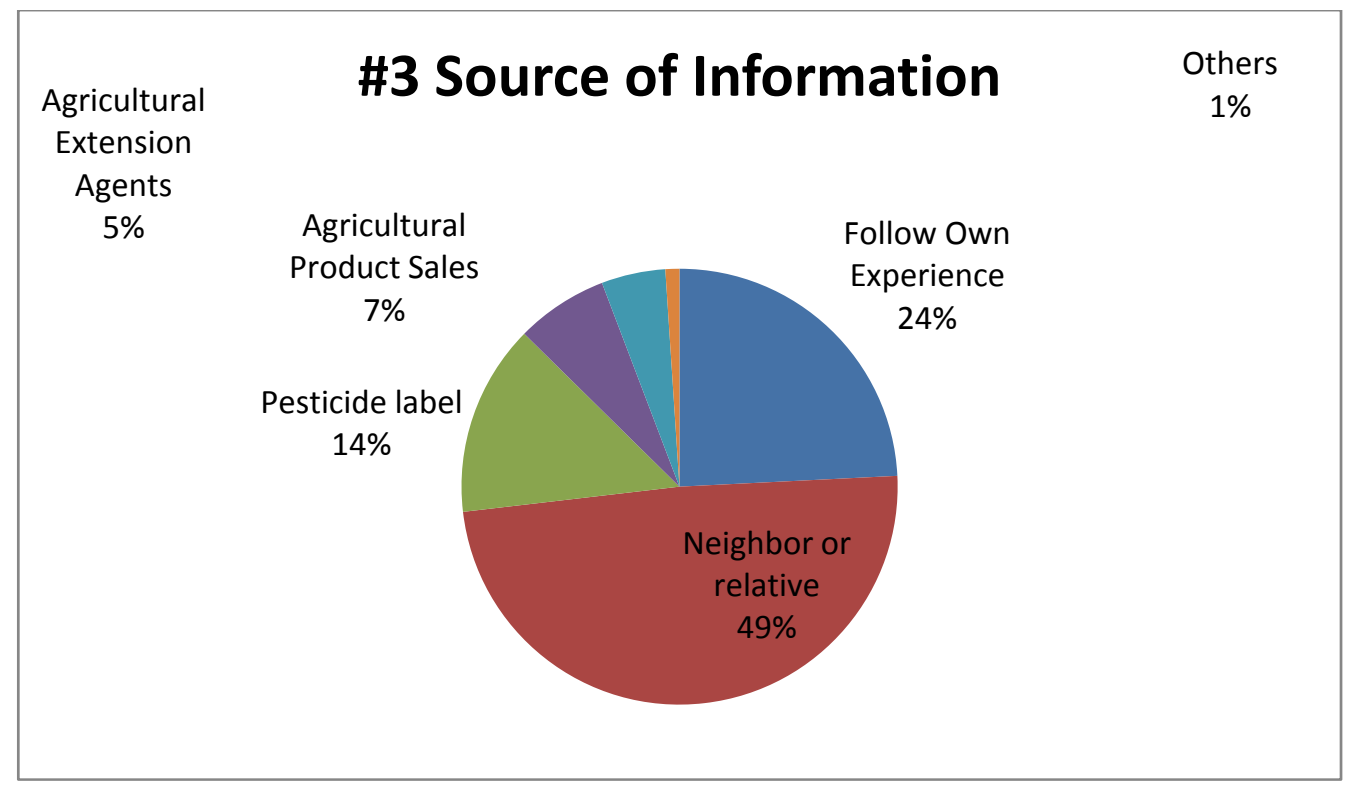

Figure 4. Divisions of Groups

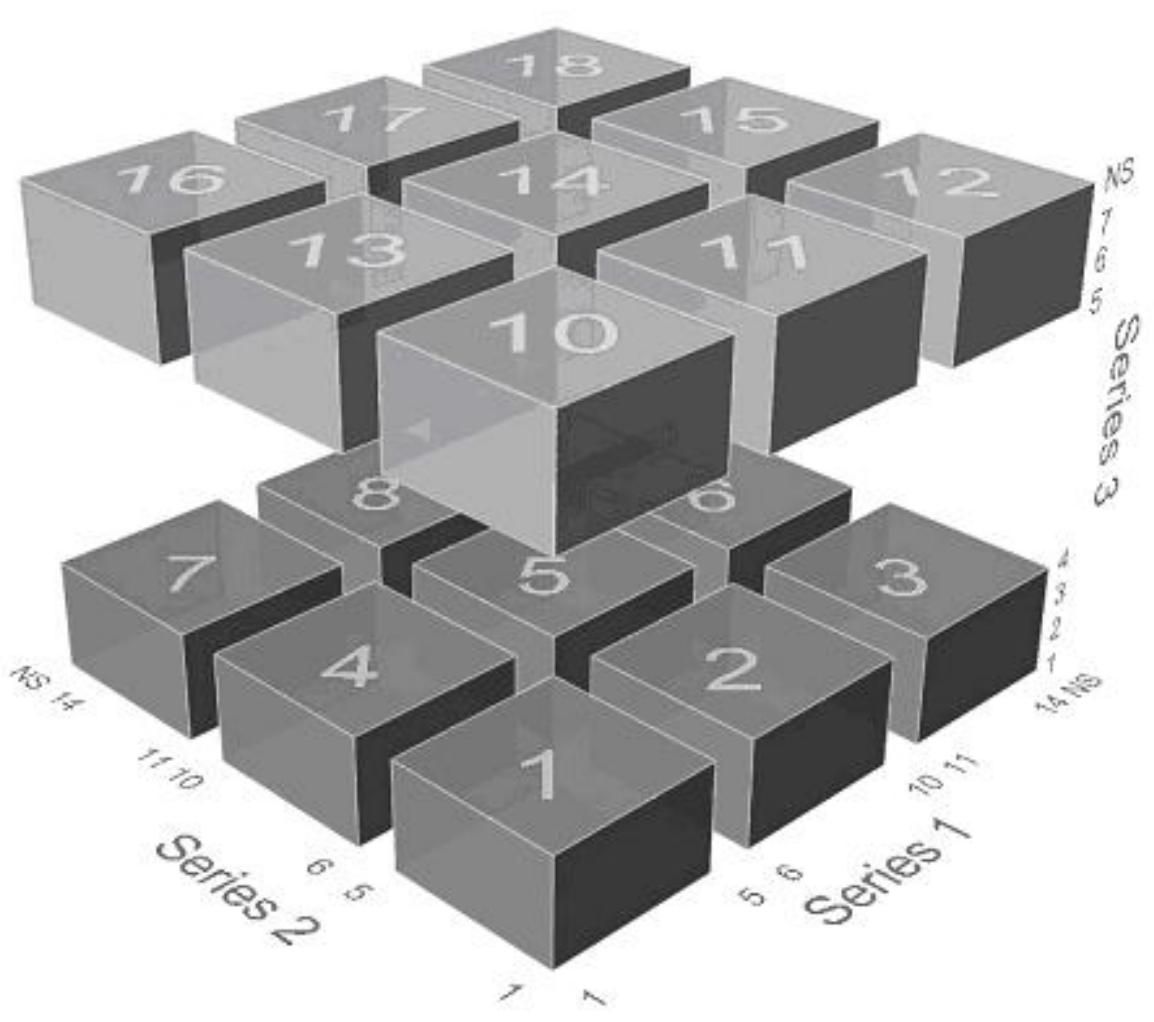

Note: Note: Group 1 consists of individuals who switch from A to B between Row 1 to 5 in Series 1 and Series 2 and switch from A to B between Row 1 to Row 4 in Series 3. 


\section{Appendix 1}

\section{Experiment Instruction}

Twenty farmers from a single village gather in the village office at the end of the interview day. We also invite the village leaders to be present in the room to witness the game so that the farmers will trust us. The village leader first explains to the farmers that we are researchers from the Center for Chinese Agricultural Policy (CCAP) is a department in Chinese Academy of Science (CAS) to conduct research on farmers who make use of genetically modified cotton. We read to the farmers the oral consent form and explain to them that everyone who agrees to participate will receive 10 Yuan to start, but they that might have the chance to lose all 10 Yuan or they might have the chance to win up to 850 Yuan. The farmers who do not wish to participate are given the opportunity to leave the room at this point in time.

We distribute an instruction sheet containing a practice question that we review with each farmer to verify that all participants understand the meanings of lottery A and lottery $\mathrm{B}$. We then prepare two bags, each of a different color, that contain numbered balls. The red bag has 10 balls numbered 1 through 10 representing the probabilities mentioned in the survey questions. The green bag contains 35 balls, each representing one of the 35 rows in the survey. We explain to the participants that after the completion of the answer sheet, they will draw one ball out of the green bag first. The number on that ball will determine which line out of the 35 that they have answered will be played. They then draw another ball out of the red bag. Depending on the lottery they have chosen for that particular line, their payoff will be determined by the second numbered ball. We use the sample answer in the instruction sheet to demonstrate how the payoff would be determined. We repeat the demonstration five times, asking the participants each time how much the payoff would be, in order to ensure that most of them understand how the game works. We instruct the participants not to communicate with each other during the game. A few 
of participants who cannot read have special assistants who read the instruction sheet and questions to them. A cover sheet is attached to the answer sheet; therefore, participants need not worry that others will see their answers. This whole process normally takes an hour to an hour and an half. 


\section{Appendix 2}

Switching points from Series 1 and Series 2 are used to estimate the curvature of the utility

function and the nonlinear probability weighting parameter $(\alpha)$ for each participant. Once we estimate the curvature of utility function, we can use switching point from Series 3 to estimate the utility curvature in the loss domain.

For any subject who switches at row $N$, we can conclude that he prefers lottery A over lottery B at row $N-1$ and prefers lottery B over lottery A at row $N$. Using a combination of switching points from Series 1 and Series 2, we will have a set of 4 inequalities and we will be able to find the ranges of $\sigma$ and $\alpha$ that satisfy these inequalities. In the case of "never switch" or "switching at row 1," we have one inequality. We follow TCN's convention by arbitrarily determine the lower/upper bound of the parameters, which is also TCN's approach. For example, when a subject switches from lottery A to lottery B at row 7 for both Series 1 and Series 2, the following inequalities should be satisfied:

$$
\begin{aligned}
& 5^{1-\sigma}+\exp \left[-(-\ln 0.3)^{\alpha}\right]\left(20^{1-\sigma}-5^{1-\sigma}\right)>2.5^{1-\sigma}+\exp \left[-(-\ln 0.1)^{\alpha}\right]\left(62.5^{1-\sigma}-2.5^{1-\sigma}\right) \\
& 5^{1-\sigma}+\exp \left[-(-\ln 0.3)^{\alpha}\right]\left(20^{1-\sigma}-5^{1-\sigma}\right)<2.5^{1-\sigma}+\exp \left[-(-\ln 0.1)^{\alpha}\right]\left(75^{1-\sigma}-2.5^{1-\sigma}\right) \\
& 15^{1-\sigma}+\exp \left[-(-\ln 0.9)^{\alpha}\right]\left(20^{1-\sigma}-15^{1-\sigma}\right)>2.5^{1-\sigma}+\exp \left[-(-\ln 0.7)^{\alpha}\right]\left(32.5^{1-\sigma}-2.5^{1-\sigma}\right) \\
& 15^{1-\sigma}+\exp \left[-(-\ln 0.9)^{\alpha}\right]\left(20^{1-\sigma}-15^{1-\sigma}\right)<2.5^{1-\sigma}+\exp \left[-(-\ln 0.7)^{\alpha}\right]\left(34^{1-\sigma}-2.5^{1-\sigma}\right) .
\end{aligned}
$$

Parameters that satisfy the above inequalities are $0.26<\sigma<0.35$ and $0.66<\alpha<0.74$. For all the parameters, we use the midpoint of each interval and take it first decimal place as the point estimate. After obtaining an estimate of $\sigma$, we use switching point from Series 3 to write out inequalities involving $\lambda$. We use the midpoint of each interval as the point estimate. More details about estimation method can be found in Tanaka et al. (2009). 

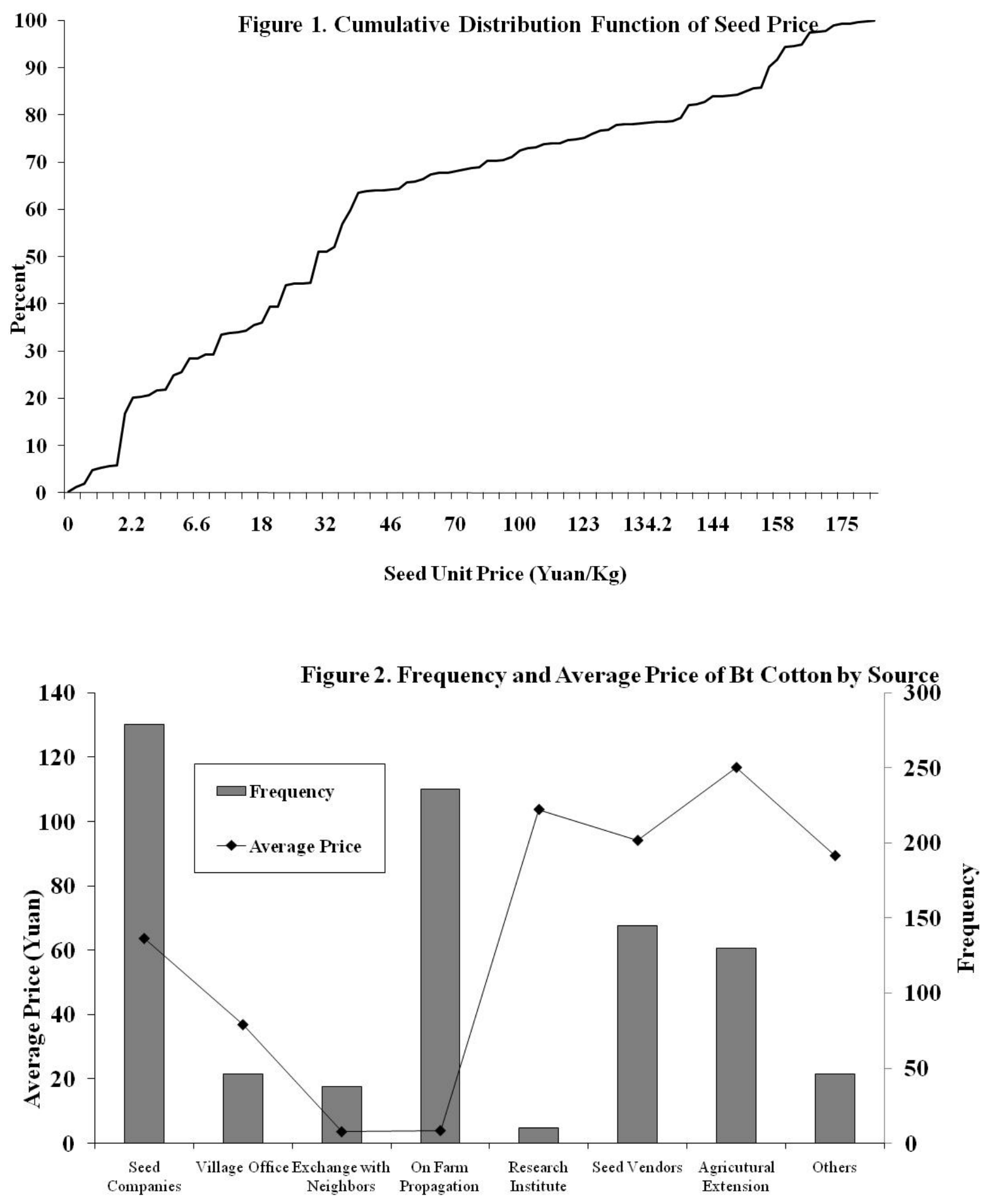

Source 
Table 1. Summary Characteristics

\begin{tabular}{lc}
\hline \hline Age & 49.52 \\
& $(8.89)$ \\
Education & 7.10 \\
& $(2.96)$ \\
Female & 0.14 \\
& $(0.35)$ \\
Size of Household & 4.49 \\
& $(1.45)$ \\
$\sigma$ (Risk Aversion) & 0.48 \\
& $(0.33)$ \\
$\lambda$ (Loss Aversion) & 3.47 \\
& $(3.92)$ \\
$\alpha$ (Probability Weighting) & 0.69 \\
& $(0.23)$ \\
Total Cotton Sown Area (Ha) & 0.54 \\
& $(0.33)$ \\
Total Land Owned (Ha) & 0.59 \\
& $(0.29)$ \\
Cotton Yield (Kg/Ha) & 3356 \\
& $(889.8)$ \\
Average Year of Bt Cotton Adoption & 1998 \\
& $(1.90)$ \\
Household Members Ever Been Poisoned & 0.40 \\
By Pesticide & $(0.49)$ \\
Observations & 320 \\
& \\
\hline \hline Note: Standard &
\end{tabular}

Note: Standard deviations are listed in parentheses. 
Table 2. Summary Characteristics By Seed Type

\begin{tabular}{|c|c|c|}
\hline & $\underline{\text { Bt Cotton }}$ & $\underline{\text { Non Bt }}$ \\
\hline Plot Size (Ha) & $\begin{array}{c}0.18 \\
(0.15)\end{array}$ & $\begin{array}{c}0.22 \\
(0.09)\end{array}$ \\
\hline Amount of Pesticide Sprayed (Kg/Ha) & $\begin{array}{l}26.37 * \\
(19.44)\end{array}$ & $\begin{array}{l}37.84 * \\
(27.34)\end{array}$ \\
\hline Total Pesticide Cost (Yuan/Ha) & $\begin{array}{c}784.46 \\
(528.55)\end{array}$ & $\begin{array}{c}936.60 \\
(877.49)\end{array}$ \\
\hline Cotton Yield (Kg/Ha) & $\begin{array}{c}3356^{*} \\
(889.8)\end{array}$ & $\begin{array}{c}2092.5^{*} \\
(408.8)\end{array}$ \\
\hline Total Cost on Seeds (Yuan/Ha) & $\begin{array}{l}552.51 * \\
(424.76)\end{array}$ & $\begin{array}{l}254.95 * \\
(145.54)\end{array}$ \\
\hline Wealth $^{\mathrm{a}}$ (100 Yuan) & $\begin{array}{l}1.03 * \\
(0.92)\end{array}$ & $\begin{array}{c}0.53^{*} \\
(0.58)\end{array}$ \\
\hline Total Number of Plots & 930 & 15 \\
\hline $\begin{array}{l}\text { Note: Standard deviations are listed in } \mathrm{p} \\
\text { difference at the } 5 \% \text { level. } \\
\text { a. Represented by the total value of dur } \\
\text { in } 2006 \text {. }\end{array}$ & itheses. *s & ically \\
\hline
\end{tabular}


Table 3. Payoff Matrix from the Experiment

\begin{tabular}{|c|c|c|}
\hline Series 1 & Lottery A & Lottery B \\
\hline 1 & 30\% winning 20 Yuan and 70\% winning 5 Yuan & 10\% winning 34 Yuan and 90\% winning 2.5 Yuan \\
\hline 2 & 30\% winning 20 Yuan and 70\% winning 5 Yuan & 10\% winning 37.5 Yuan and 90\% winning 2.5 Yuan \\
\hline 3 & 30\% winning 20 Yuan and 70\% winning 5 Yuan & 10\% winning 41.5 Yuan and 90\% winning 2.5 Yuan \\
\hline 4 & 30\% winning 20 Yuan and 70\% winning 5 Yuan & 10\% winning 46.5 Yuan and 90\% winning 2.5 Yuan \\
\hline 5 & 30\% winning 20 Yuan and 70\% winning 5 Yuan & 10\% winning 53 Yuan and 90\% winning 2.5 Yuan \\
\hline 6 & 30\% winning 20 Yuan and 70\% winning 5 Yuan & 10\% winning 62.5 Yuan and 90\% winning 2.5 Yuan \\
\hline 7 & 30\% winning 20 Yuan and 70\% winning 5 Yuan & 10\% winning 75 Yuan and 90\% winning 2.5 Yuan \\
\hline 8 & 30\% winning 20 Yuan and 70\% winning 5 Yuan & 10\% winning 92.5 Yuan and 90\% winning 2.5 Yuan \\
\hline 9 & 30\% winning 20 Yuan and 70\% winning 5 Yuan & 10\% winning 110 Yuan and 90\% winning 2.5 Yuan \\
\hline 10 & 30\% winning 20 Yuan and 70\% winning 5 Yuan & 10\% winning 150 Yuan and 90\% winning 2.5 Yuan \\
\hline 11 & 30\% winning 20 Yuan and 70\% winning 5 Yuan & 10\% winning 200 Yuan and 90\% winning 2.5 Yuan \\
\hline 12 & 30\% winning 20 Yuan and 70\% winning 5 Yuan & 10\% winning 300 Yuan and 90\% winning 2.5 Yuan \\
\hline 13 & 30\% winning 20 Yuan and 70\% winning 5 Yuan & 10\% winning 500 Yuan and 90\% winning 2.5 Yuan \\
\hline 14 & 30\% winning 20 Yuan and 70\% winning 5 Yuan & 10\% winning 850 Yuan and 90\% winning 2.5 Yuan \\
\hline Series 2 & Lottery A & Lottery B \\
\hline 1 & $90 \%$ winning 20 Yuan and $10 \%$ winning 15 Yuan & 70\% winning 27 Yuan and 30\% winning 2.5 Yuan \\
\hline 2 & 90\% winning 20 Yuan and 10\% winning 15 Yuan & 70\% winning 28 Yuan and 30\% winning 2.5 Yuan \\
\hline 3 & 90\% winning 20 Yuan and $10 \%$ winning 15 Yuan & 70\% winning 29 Yuan and 30\% winning 2.5 Yuan \\
\hline 4 & 90\% winning 20 Yuan and 10\% winning 15 Yuan & 70\% winning 30 Yuan and 30\% winning 2.5 Yuan \\
\hline 5 & 90\% winning 20 Yuan and 10\% winning 15 Yuan & 70\% winning 31 Yuan and 30\% winning 2.5 Yuan \\
\hline 6 & 90\% winning 20 Yuan and 10\% winning 15 Yuan & $70 \%$ winning 32.5 Yuan and 30\% winning 2.5 Yuan \\
\hline 7 & 90\% winning 20 Yuan and 10\% winning 15 Yuan & 70\% winning 34 Yuan and 30\% winning 2.5 Yuan \\
\hline 8 & 90\% winning 20 Yuan and $10 \%$ winning 15 Yuan & 70\% winning 36 Yuan and 30\% winning 2.5 Yuan \\
\hline 9 & 90\% winning 20 Yuan and 10\% winning 15 Yuan & 70\% winning 38.5 Yuan and 30\% winning 2.5 Yuan \\
\hline 10 & 90\% winning 20 Yuan and $10 \%$ winning 15 Yuan & 70\% winning 41.5 Yuan and 30\% winning 2.5 Yuan \\
\hline 11 & 90\% winning 20 Yuan and 10\% winning 15 Yuan & 70\% winning 45 Yuan and 30\% winning 2.5 Yuan \\
\hline 12 & 90\% winning 20 Yuan and $10 \%$ winning 15 Yuan & 70\% winning 50 Yuan and 30\% winning 2.5 Yuan \\
\hline 13 & 90\% winning 20 Yuan and $10 \%$ winning 15 Yuan & 70\% winning 55 Yuan and 30\% winning 2.5 Yuan \\
\hline 14 & 90\% winning 20 Yuan and 10\% winning 15 Yuan & 70\% winning 65 Yuan and 30\% winning 2.5 Yuan \\
\hline Series 3 & Lottery A & Lottery B \\
\hline 1 & $50 \%$ winning 12.5 Yuan and 50\% losing 2 Yuan & 50\% winning 15 Yuan and 50\% losing 10 Yuan \\
\hline 2 & $50 \%$ winning 2 Yuan and 50\% losing 2 Yuan & 50\% winning 15 Yuan and 50\% losing 10 Yuan \\
\hline 3 & $50 \%$ winning 0.5 Yuan and 50\% losing 2 Yuan & 50\% winning 15 Yuan and 50\% losing 10 Yuan \\
\hline 4 & $50 \%$ winning 0.5 Yuan and 50\% losing 2 Yuan & 50\% winning 15 Yuan and 50\% losing 8 Yuan \\
\hline 5 & $50 \%$ winning 0.5 Yuan and 50\% losing 4 Yuan & 50\% winning 15 Yuan and 50\% losing 8 Yuan \\
\hline 6 & $50 \%$ winning 0.5 Yuan and 50\% losing 4 Yuan & 50\% winning 15 Yuan and 50\% losing 7 Yuan \\
\hline 7 & $50 \%$ winning 0.5 Yuan and 50\% losing 4 Yuan & 50\% winning 15 Yuan and 50\% losing 5.5 Yuan \\
\hline
\end{tabular}


Table 4. OLS Regression of Pesticide Use (Kilogram/Hectare)

\begin{tabular}{|c|c|c|c|c|}
\hline & $(1)$ & 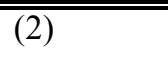 & (3) & (4) \\
\hline \multirow{2}{*}{\multicolumn{2}{|c|}{$\begin{array}{l}\sigma \\
\text { (value function curvature) }\end{array}$}} & $7.244 * * *$ & $7.423 * * *$ & $7.450 * * *$ \\
\hline & & $(2.453)$ & $(2.443)$ & $(2.455)$ \\
\hline \multicolumn{2}{|l|}{$\lambda$} & $-0.502 * * *$ & $-0.530 * * *$ & $-0.525 * * *$ \\
\hline \multicolumn{2}{|l|}{ (loss aversion) } & $(0.188)$ & $(0.189)$ & $(0.182)$ \\
\hline \multicolumn{2}{|l|}{$\alpha$} & $7.048^{*}$ & $6.614^{*}$ & 5.989 \\
\hline \multicolumn{2}{|l|}{ (probability weighting) } & (3.958) & (3.912) & (3.963) \\
\hline \multirow[t]{2}{*}{ Age } & -0.118 & -0.105 & -0.124 & -0.116 \\
\hline & $(0.139)$ & $(0.132)$ & $(0.132)$ & $(0.135)$ \\
\hline \multirow[t]{2}{*}{ Education (Years) } & $-0.726^{* *}$ & $-0.650^{*}$ & $-0.622 *$ & -0.542 \\
\hline & $(0.358)$ & $(0.346)$ & $(0.345)$ & $(0.333)$ \\
\hline \multirow[t]{2}{*}{ Plot Size (Ha) } & $-9.441 * * *$ & $-7.497 * *$ & $-8.151 * *$ & $-8.858 * * *$ \\
\hline & $(3.591)$ & $(3.089)$ & $(3.162)$ & $(3.262)$ \\
\hline \multirow[t]{2}{*}{ Price of Pesticide } & $-0.377 * * *$ & $-0.389 * * *$ & $-0.388 * * *$ & $-0.371 * * *$ \\
\hline & $(0.061)$ & $(0.062)$ & $(0.062)$ & $(0.063)$ \\
\hline \multirow[t]{2}{*}{$\mathrm{Bt}^{\mathrm{a}}$} & $-19.51 * *$ & $-21.48 * *$ & $-21.77 * *$ & $-25.92 * * *$ \\
\hline & $(8.135)$ & $(8.785)$ & $(8.766)$ & $(9.516)$ \\
\hline \multirow[t]{2}{*}{ Experience with Bt (Years) } & 0.99 & 1.084 & $1.147^{*}$ & 1.093 \\
\hline & $(0.649)$ & $(0.681)$ & $(0.682)$ & $(0.679)$ \\
\hline \multirow[t]{2}{*}{ Training $^{\mathrm{b}}$} & & & -3.27 & -2.803 \\
\hline & & & $(2.086)$ & $(2.095)$ \\
\hline \multirow[t]{2}{*}{ Bollworm Severity $^{c}$} & & & & 0.0805 \\
\hline & & & & $(0.050)$ \\
\hline \multirow[t]{2}{*}{ Mirid Severity ${ }^{\mathrm{d}}$} & & & & 0.0438 \\
\hline & & & & $(0.035)$ \\
\hline Observations & 941 & 930 & 930 & 925 \\
\hline R-squared & 0.327 & 0.362 & 0.367 & 0.384 \\
\hline
\end{tabular}

Note: Robust standard errors are listed in parentheses. * significant at the $10 \%$ level; ${ }^{* *}$ significant at the $5 \%$ level; *** significant at the $1 \%$ level. All regressions include village fixed effects. Standard errors are clustered at the individual level. The unit of observation for the regression is the plot. In particular, we have 5 farmers (11 plots) who did not participate in the experiment.

a. Bt Cotton equals 1 if $\mathrm{Bt}$ cotton was planted in the plot, 0 if non-Bt cotton was planted in the plot.

b. Training equals 1 if the farmer had ever attended a training, 0 if he/she never attended a training.

c. It is proxied by an answer to a yield loss perception question: What do you think your potential yield loss will be if you do not control for bollworm? The answer can range from 0 to 100 . The higher value indicates the worse bollworm severity.

d. It is proxied by an answer to a yield loss perception question: What do you think your potential yield loss will be if you do not control for mirids? The answer can range from 0 to 100 . The higher value indicates the worse mirid severity. 
Table 5. OLS Regression of Pesticide Use (Kilogram/Hectare)

\begin{tabular}{|c|c|c|}
\hline & (1) & (2) \\
\hline $\begin{array}{l}\sigma \\
\text { (value function curvature) }\end{array}$ & $\begin{array}{l}7.597 * * * \\
(2.501)\end{array}$ & $\begin{array}{l}7.454 * * * \\
(2.520)\end{array}$ \\
\hline$\lambda$ & $-0.579 * * *$ & $-0.611 * * *$ \\
\hline (loss aversion) & $(0.189)$ & $(0.189)$ \\
\hline$\alpha$ & 5.400 & 4.967 \\
\hline (probability weighting) & (3.915) & (3.874) \\
\hline \multirow[t]{2}{*}{ Age } & -0.113 & -0.103 \\
\hline & $(0.137)$ & $(0.137)$ \\
\hline \multirow[t]{2}{*}{ Education (years) } & -0.357 & -0.398 \\
\hline & $(0.357)$ & $(0.356)$ \\
\hline \multirow[t]{2}{*}{ Plot Size (Ha) } & $-10.24 * * *$ & $-9.495 * * *$ \\
\hline & $(3.693)$ & $(3.629)$ \\
\hline \multirow[t]{2}{*}{ Price of Pesticide } & $-0.456 * * *$ & $-0.450 * * *$ \\
\hline & $(0.087)$ & $(0.086)$ \\
\hline \multirow[t]{2}{*}{ Training } & $-4.676^{*}$ & $-4.975^{*}$ \\
\hline & (2.619) & $(2.704)$ \\
\hline \multirow[t]{2}{*}{ Price of Seed } & 0.017 & \\
\hline & $(0.028)$ & \\
\hline \multicolumn{3}{|l|}{ Source } \\
\hline \multirow[t]{2}{*}{ Seed Companies } & & 3.973 \\
\hline & & $(4.860)$ \\
\hline \multirow[t]{2}{*}{ Village Office } & & -0.279 \\
\hline & & (5.497) \\
\hline \multirow[t]{2}{*}{ Exchange w/ Neighbors } & & 0.323 \\
\hline & & $(5.134)$ \\
\hline \multirow[t]{2}{*}{ Saved Seeds } & & 2.044 \\
\hline & & $(4.750)$ \\
\hline \multirow[t]{2}{*}{ Research Inst } & & -4.963 \\
\hline & & (6.149) \\
\hline \multirow[t]{2}{*}{ Seed Vendors } & & -0.738 \\
\hline & & $(4.280)$ \\
\hline \multirow[t]{2}{*}{ Agri. Extension } & & 2.582 \\
\hline & & $(4.843)$ \\
\hline Observations & 920 & 920 \\
\hline R-squared & 0.352 & 0.359 \\
\hline
\end{tabular}

Note: All non-Bt cotton plots are excluded from the regressions. Robust standard errors are listed in parentheses. * significant at $10 \%$; $* *$ significant at $5 \% ; * * *$ significant at $1 \%$. All regressions include village fixed effects. Standard errors are clustered at the individual level. 
Table 6. OLS Regression of Pesticide Use (Kilogram/Hectare)

\begin{tabular}{lll}
\hline \hline & $(1)$ & $(2)$ \\
\hline$\sigma$ & $6.587^{* * *}$ & $6.755^{* * *}$ \\
(value function curvature) & $(2.166)$ & $(2.226)$ \\
$\lambda$ & $-0.440^{* *}$ & $-0.426^{*}$ \\
(loss aversion) & $(0.204)$ & $(0.209)$ \\
$\alpha$ & 4.497 & 4.181 \\
(probability weighting) & $(5.346)$ & $(5.417)$ \\
Age & -0.154 & -0.157 \\
& $(0.168)$ & $(0.167)$ \\
Education (years) & -0.247 & -0.266 \\
& $(0.283)$ & $(0.286)$ \\
Total Landholing (Ha) & -4.220 & -4.230 \\
& $(2.911)$ & $(2.888)$ \\
Price of Pesticide & $-0.461^{* * *}$ & $-0.460^{* * *}$ \\
& $(0.086)$ & $(0.093)$ \\
Training & $-4.167^{*}$ & $-4.602^{* *}$ \\
& $(2.020)$ & $(1.991)$ \\
Extension Agent $1^{\mathrm{a}}$ & $-6.390^{*}$ & \\
Extension Agent $3^{\mathrm{b}}$ & $(3.626)$ & \\
Observations & & -1.451 \\
R-squared & 311 & $(2.584)$ \\
\hline \hline Note: Robust & 0.32 & 311 \\
\hline
\end{tabular}

Note: Robust standard errors are listed in parentheses. ${ }^{*}$ significant at $10 \%$;* significant at $5 \%$; ** significant at $1 \%$. Unit of observation is at the household level. All traditional cotton plots are excluded when compiling total pesticide use and landholding. All regressions include village fixed effects. Standard errors are clustered at the village level.

a. This variable equals to 1 if the farmer reported having extension agent as number 1 source of information when deiciding how much pesticide to spray

b. This variable equals to 1 if the farmer reported having extension agent as top 3 source of information when deiciding how much pesticide to spray 
Table 7. Robustness Checks for Pesticide Use

\begin{tabular}{llll}
\hline \hline Dependent Variable & $\begin{array}{l}\text { Ln}(\text { Pesticide Use) } \\
(1)\end{array}$ & $\begin{array}{l}\text { Pesticide Expenditure } \\
(\text { Yuan/Ha) }\end{array}$ & $\begin{array}{l}\text { Pesticide Use } \\
(\mathrm{Kg} / \mathrm{Ha})\end{array}$ \\
\hline$\sigma$ & $0.242^{* *}$ & $211.7^{* * *}$ & $6.793^{* * *}$ \\
(value function curvature) & $(0.098)$ & $(69.360)$ & $(2.241)$ \\
$\lambda$ & $-0.0150^{*}$ & $-14.34^{* *}$ & $-0.414^{*}$ \\
(loss aversion) & $(0.008)$ & $(5.686)$ & $(0.206)$ \\
$\alpha$ & 0.142 & 118.100 & 4.274 \\
(probability weighting) & $(0.140)$ & $(112.400)$ & $(5.363)$ \\
Age & -0.004 & -3.235 & -0.155 \\
& $(0.004)$ & $(3.821)$ & $(0.168)$ \\
Education (years) & -0.022 & $-22.22^{*}$ & -0.262 \\
& $(0.013)$ & $(12.020)$ & $(0.288)$ \\
Plot Size (Ha) & $-0.217^{*}$ & $-193.4^{* *}$ & -4.213 \\
Price of Pesticide & $(0.123)$ & $(78.590)$ & $(2.866)$ \\
& $-0.0169^{* * *}$ & & $-0.458^{* * *}$ \\
Experience With Bt (Years) & $(0.002)$ & & $(0.094)$ \\
& 0.035 & 27.780 & \\
Bt & $(0.022)$ & $(19.320)$ & \\
Training & $-0.659^{* * *}$ & $-616.1^{* *}$ & \\
Observations & $(0.216)$ & $(263.600)$ & \\
R-squared & -0.122 & -87.540 & $-4.839^{* *}$ \\
\hline \hline No: Robust san & $(64.880)$ & $(1.898)$ \\
& $(0.081)$ & 930 & 311 \\
& 930 & 0.319 & 0.316 \\
\hline
\end{tabular}

Note: Robust standard errors are listed in parentheses. ${ }^{*}$ significant at $10 \%$; $*$ significant at $5 \%$;** significant at $1 \%$. Unit of observation is at the plot level for Columns 1 and 2 , but it is at the household level for Column 3. All traditional cotton plots are excluded when compiling total pesticide use and landholding for Column 3. In Column 3, the plot size variable is replaced by total landholding. All regressions include village fixed effects. Standard errors are clustered at the village level. 
Table 8. Loss Aversion and Pesticide Use

\begin{tabular}{|c|c|c|}
\hline \multirow[t]{2}{*}{ Dependent Variable } & $\overline{L n}$ (Pesticide Use) & $\begin{array}{l}\text { Pesticide Expenditure } \\
\text { (Yuan/Ha) }\end{array}$ \\
\hline & (1) & (2) \\
\hline$\sigma$ & $5.876^{*}$ & $5.947^{*}$ \\
\hline (value function curvature) & $(2.827)$ & $(2.861)$ \\
\hline$\alpha$ & 5.437 & 4.577 \\
\hline (probability weighting) & $(5.390)$ & $(5.720)$ \\
\hline$\lambda(2$ nd Quartile) & -0.610 & -0.102 \\
\hline $0.83<\lambda<2.02$ & $(3.260)$ & (3.130) \\
\hline$\lambda(3$ rd Quartile) & -1.955 & -1.332 \\
\hline $2.02<\lambda<3.22$ & $(2.764)$ & $(3.205)$ \\
\hline$\lambda$ (4th Quartile) & -2.247 & -1.518 \\
\hline $3.22<\lambda$ & $(2.531)$ & $(2.412)$ \\
\hline$\lambda(\text { (2nd Quartile) })^{*}$ Med Cost ${ }^{\mathrm{a}}$ & & $\begin{array}{l}-1.575 \\
(1.680)\end{array}$ \\
\hline$\lambda(3$ rd Quartile)*Med Cost & & $\begin{array}{l}-1.581 \\
(1.424)\end{array}$ \\
\hline$\lambda(4$ th Quartile)*Med Cost & & $\begin{array}{l}-1.826^{* * * *} \\
(0.458)\end{array}$ \\
\hline Observations & 303 & 303 \\
\hline R-squared & 0.306 & 0.313 \\
\hline
\end{tabular}

Note: Robust standard errors are listed in parentheses. * significant at $10 \%$; $* *$ significant at $5 \%$; *** significant at $1 \%$. Unit of observation is at the household level. We exclude individuals (6 farmers) whose last pesticide poisoning experience occurred in 2006 given that they would not have the chance to adjust their pesticide use after the most recent pesticide poisoning experience. All regressions control for village fixed effects, age, education, landholding $\&$ training. The default group are those who are in the first quartile (least loss averse). Standard errors are clustered at the village level.

a. Med cost equals to all costs (both medical and imputed labor cost) incurred due to last pesticide poisoning episode in 100 Yuan. 


\section{Appendix 1}

\section{Experiment Instruction}

Twenty farmers from a single village gather in the village office at the end of the interview day. We also invite the village leaders to be present in the room to witness the game so that the farmers will trust us. The village leader first explains to the farmers that we are researchers from the Center for Chinese Agricultural Policy (CCAP) is a department in Chinese Academy of Science (CAS) to conduct research on farmers who make use of genetically modified cotton. We read to the farmers the oral consent form and explain to them that everyone who agrees to participate will receive 10 Yuan to start, but they that might have the chance to lose all 10 Yuan or they might have the chance to win up to 850 Yuan. The farmers who do not wish to participate are given the opportunity to leave the room at this point in time.

We distribute an instruction sheet containing a practice question that we review with each farmer to verify that all participants understand the meanings of lottery A and lottery B. We then prepare two bags, each of a different color, that contain numbered balls. The red bag has 10 balls numbered 1 through 10 representing the probabilities mentioned in the survey questions. The green bag contains 35 balls, each representing one of the 35 rows in the survey. We explain to the participants that after the completion of the answer sheet, they will draw one ball out of the green bag first. The number on that ball will determine which line out of the 35 that they have answered will be played. They then draw another ball out of the red bag. Depending on the lottery they have chosen for that particular line, their payoff will be determined by the second numbered ball. We use the sample answer in the instruction sheet to demonstrate how the payoff would be determined. We repeat the demonstration five times, asking the participants each time how much the payoff would be, in order to ensure that most of them understand how the game works. We instruct the participants not to communicate with each other during the game. A few 
of participants who cannot read have special assistants who read the instruction sheet and questions to them. A cover sheet is attached to the answer sheet; therefore, participants need not worry that others will see their answers. This whole process normally takes an hour to an hour and an half. 


\section{Appendix 2}

Switching points from Series 1 and Series 2 are used to estimate the curvature of the utility

function and the nonlinear probability weighting parameter $(\alpha)$ for each participant. Once we estimate the curvature of utility function, we can use switching point from Series 3 to estimate the utility curvature in the loss domain.

For any subject who switches at row $N$, we can conclude that he prefers lottery A over lottery B at row $N$ - 1 and prefers lottery B over lottery A at row $N$. Using a combination of switching points from Series 1 and Series 2, we will have a set of 4 inequalities and we will be able to find the ranges of $\sigma$ and $\alpha$ that satisfy these inequalities. In the case of "never switch" or "switching at row 1," we have one inequality. We follow TCN's convention by arbitrarily determine the lower/upper bound of the parameters, which is also TCN's approach. For example, when a subject switches from lottery A to lottery B at row 7 for both Series 1 and Series 2, the following inequalities should be satisfied:

$$
\begin{aligned}
& 5^{1-\sigma}+\exp \left[-(-\ln 0.3)^{\alpha}\right]\left(20^{1-\sigma}-5^{1-\sigma}\right)>2.5^{1-\sigma}+\exp \left[-(-\ln 0.1)^{\alpha}\right]\left(62.5^{1-\sigma}-2.5^{1-\sigma}\right) \\
& 5^{1-\sigma}+\exp \left[-(-\ln 0.3)^{\alpha}\right]\left(20^{1-\sigma}-5^{1-\sigma}\right)<2.5^{1-\sigma}+\exp \left[-(-\ln 0.1)^{\alpha}\right]\left(75^{1-\sigma}-2.5^{1-\sigma}\right) \\
& 15^{1-\sigma}+\exp \left[-(-\ln 0.9)^{\alpha}\right]\left(20^{1-\sigma}-15^{1-\sigma}\right)>2.5^{1-\sigma}+\exp \left[-(-\ln 0.7)^{\alpha}\right]\left(32.5^{1-\sigma}-2.5^{1-\sigma}\right) \\
& 15^{1-\sigma}+\exp \left[-(-\ln 0.9)^{\alpha}\right]\left(20^{1-\sigma}-15^{1-\sigma}\right)<2.5^{1-\sigma}+\exp \left[-(-\ln 0.7)^{\alpha}\right]\left(34^{1-\sigma}-2.5^{1-\sigma}\right) .
\end{aligned}
$$

Parameters that satisfy the above inequalities are $0.26<\sigma<0.35$ and $0.66<\alpha<0.74$. For all the parameters, we use the midpoint of each interval and take it first decimal place as the point estimate. After obtaining an estimate of $\sigma$, we use switching point from Series 3 to write out inequalities involving $\lambda$. We use the midpoint of each interval as the point estimate. More details about estimation method can be found in Tanaka et al. (2009). 
Table 1. Summary Characteristics

\begin{tabular}{lc}
\hline \hline Age & 49.52 \\
& $(8.89)$ \\
Education & 7.10 \\
& $(2.96)$ \\
Female & 0.14 \\
& $(0.35)$ \\
Size of Household & 4.49 \\
& $(1.45)$ \\
$\sigma$ (Risk Aversion) & 0.48 \\
& $(0.33)$ \\
$\lambda$ (Loss Aversion) & 3.47 \\
& $(3.92)$ \\
$\alpha$ (Probability Weighting) & 0.69 \\
& $(0.23)$ \\
Total Cotton Sown Area (Ha) & 0.54 \\
& $(0.33)$ \\
Total Land Owned (Ha) & 0.59 \\
& $(0.29)$ \\
Cotton Yield (Kg/Ha) & 3356 \\
& $(889.8)$ \\
Average Year of Bt Cotton Adoption & 1998 \\
& $(1.90)$ \\
Household Members Ever Been Poisoned & 0.40 \\
By Pesticide & $(0.49)$ \\
Observations & 320 \\
& \\
\hline \hline Note: Standard &
\end{tabular}

Note: Standard deviations are listed in parentheses. 
Table 2. Summary Characteristics By Seed Type

\begin{tabular}{|c|c|c|}
\hline & $\underline{\text { Bt Cotton }}$ & $\underline{\text { Non Bt }}$ \\
\hline Plot Size (Ha) & $\begin{array}{c}0.18 \\
(0.15)\end{array}$ & $\begin{array}{c}0.22 \\
(0.09)\end{array}$ \\
\hline Amount of Pesticide Sprayed (Kg/Ha) & $\begin{array}{l}26.37 * \\
(19.44)\end{array}$ & $\begin{array}{l}37.84 * \\
(27.34)\end{array}$ \\
\hline Total Pesticide Cost (Yuan/Ha) & $\begin{array}{c}784.46 \\
(528.55)\end{array}$ & $\begin{array}{c}936.60 \\
(877.49)\end{array}$ \\
\hline Cotton Yield (Kg/Ha) & $\begin{array}{c}3356^{*} \\
(889.8)\end{array}$ & $\begin{array}{c}2092.5^{*} \\
(408.8)\end{array}$ \\
\hline Total Cost on Seeds (Yuan/Ha) & $\begin{array}{l}552.51 * \\
(424.76)\end{array}$ & $\begin{array}{l}254.95 * \\
(145.54)\end{array}$ \\
\hline Wealth $^{\mathrm{a}}$ (100 Yuan) & $\begin{array}{l}1.03 * \\
(0.92)\end{array}$ & $\begin{array}{c}0.53^{*} \\
(0.58)\end{array}$ \\
\hline Total Number of Plots & 930 & 15 \\
\hline $\begin{array}{l}\text { Note: Standard deviations are listed in } \mathrm{p} \\
\text { difference at the } 5 \% \text { level. } \\
\text { a. Represented by the total value of dur } \\
\text { in } 2006 \text {. }\end{array}$ & itheses. *s & ically \\
\hline
\end{tabular}


Table 3. Payoff Matrix from the Experiment

\begin{tabular}{|c|c|c|}
\hline Series 1 & Lottery A & Lottery B \\
\hline 1 & 30\% winning 20 Yuan and 70\% winning 5 Yuan & 10\% winning 34 Yuan and 90\% winning 2.5 Yuan \\
\hline 2 & 30\% winning 20 Yuan and 70\% winning 5 Yuan & 10\% winning 37.5 Yuan and 90\% winning 2.5 Yuan \\
\hline 3 & 30\% winning 20 Yuan and 70\% winning 5 Yuan & 10\% winning 41.5 Yuan and 90\% winning 2.5 Yuan \\
\hline 4 & 30\% winning 20 Yuan and 70\% winning 5 Yuan & 10\% winning 46.5 Yuan and 90\% winning 2.5 Yuan \\
\hline 5 & 30\% winning 20 Yuan and 70\% winning 5 Yuan & 10\% winning 53 Yuan and 90\% winning 2.5 Yuan \\
\hline 6 & 30\% winning 20 Yuan and 70\% winning 5 Yuan & 10\% winning 62.5 Yuan and 90\% winning 2.5 Yuan \\
\hline 7 & 30\% winning 20 Yuan and 70\% winning 5 Yuan & 10\% winning 75 Yuan and 90\% winning 2.5 Yuan \\
\hline 8 & 30\% winning 20 Yuan and 70\% winning 5 Yuan & 10\% winning 92.5 Yuan and 90\% winning 2.5 Yuan \\
\hline 9 & 30\% winning 20 Yuan and 70\% winning 5 Yuan & 10\% winning 110 Yuan and 90\% winning 2.5 Yuan \\
\hline 10 & 30\% winning 20 Yuan and 70\% winning 5 Yuan & 10\% winning 150 Yuan and 90\% winning 2.5 Yuan \\
\hline 11 & 30\% winning 20 Yuan and 70\% winning 5 Yuan & 10\% winning 200 Yuan and 90\% winning 2.5 Yuan \\
\hline 12 & 30\% winning 20 Yuan and 70\% winning 5 Yuan & 10\% winning 300 Yuan and 90\% winning 2.5 Yuan \\
\hline 13 & 30\% winning 20 Yuan and 70\% winning 5 Yuan & 10\% winning 500 Yuan and 90\% winning 2.5 Yuan \\
\hline 14 & 30\% winning 20 Yuan and 70\% winning 5 Yuan & 10\% winning 850 Yuan and 90\% winning 2.5 Yuan \\
\hline Series 2 & Lottery A & Lottery B \\
\hline 1 & $90 \%$ winning 20 Yuan and $10 \%$ winning 15 Yuan & 70\% winning 27 Yuan and 30\% winning 2.5 Yuan \\
\hline 2 & 90\% winning 20 Yuan and 10\% winning 15 Yuan & 70\% winning 28 Yuan and 30\% winning 2.5 Yuan \\
\hline 3 & 90\% winning 20 Yuan and $10 \%$ winning 15 Yuan & 70\% winning 29 Yuan and 30\% winning 2.5 Yuan \\
\hline 4 & 90\% winning 20 Yuan and 10\% winning 15 Yuan & 70\% winning 30 Yuan and 30\% winning 2.5 Yuan \\
\hline 5 & 90\% winning 20 Yuan and 10\% winning 15 Yuan & 70\% winning 31 Yuan and 30\% winning 2.5 Yuan \\
\hline 6 & 90\% winning 20 Yuan and 10\% winning 15 Yuan & $70 \%$ winning 32.5 Yuan and 30\% winning 2.5 Yuan \\
\hline 7 & 90\% winning 20 Yuan and 10\% winning 15 Yuan & 70\% winning 34 Yuan and 30\% winning 2.5 Yuan \\
\hline 8 & 90\% winning 20 Yuan and $10 \%$ winning 15 Yuan & 70\% winning 36 Yuan and 30\% winning 2.5 Yuan \\
\hline 9 & 90\% winning 20 Yuan and 10\% winning 15 Yuan & 70\% winning 38.5 Yuan and 30\% winning 2.5 Yuan \\
\hline 10 & 90\% winning 20 Yuan and $10 \%$ winning 15 Yuan & 70\% winning 41.5 Yuan and 30\% winning 2.5 Yuan \\
\hline 11 & 90\% winning 20 Yuan and 10\% winning 15 Yuan & 70\% winning 45 Yuan and 30\% winning 2.5 Yuan \\
\hline 12 & 90\% winning 20 Yuan and $10 \%$ winning 15 Yuan & 70\% winning 50 Yuan and 30\% winning 2.5 Yuan \\
\hline 13 & 90\% winning 20 Yuan and $10 \%$ winning 15 Yuan & 70\% winning 55 Yuan and 30\% winning 2.5 Yuan \\
\hline 14 & 90\% winning 20 Yuan and 10\% winning 15 Yuan & 70\% winning 65 Yuan and 30\% winning 2.5 Yuan \\
\hline Series 3 & Lottery A & Lottery B \\
\hline 1 & $50 \%$ winning 12.5 Yuan and 50\% losing 2 Yuan & 50\% winning 15 Yuan and 50\% losing 10 Yuan \\
\hline 2 & $50 \%$ winning 2 Yuan and 50\% losing 2 Yuan & 50\% winning 15 Yuan and 50\% losing 10 Yuan \\
\hline 3 & $50 \%$ winning 0.5 Yuan and 50\% losing 2 Yuan & 50\% winning 15 Yuan and 50\% losing 10 Yuan \\
\hline 4 & $50 \%$ winning 0.5 Yuan and 50\% losing 2 Yuan & 50\% winning 15 Yuan and 50\% losing 8 Yuan \\
\hline 5 & $50 \%$ winning 0.5 Yuan and 50\% losing 4 Yuan & 50\% winning 15 Yuan and 50\% losing 8 Yuan \\
\hline 6 & $50 \%$ winning 0.5 Yuan and 50\% losing 4 Yuan & 50\% winning 15 Yuan and 50\% losing 7 Yuan \\
\hline 7 & $50 \%$ winning 0.5 Yuan and 50\% losing 4 Yuan & 50\% winning 15 Yuan and 50\% losing 5.5 Yuan \\
\hline
\end{tabular}


Table 4. OLS Regression of Pesticide Use (Kilogram/Hectare)

\begin{tabular}{|c|c|c|c|c|}
\hline & $(1)$ & 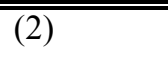 & (3) & (4) \\
\hline \multirow{2}{*}{\multicolumn{2}{|c|}{$\begin{array}{l}\sigma \\
\text { (value function curvature) }\end{array}$}} & $7.244 * * *$ & $7.423 * * *$ & $7.450 * * *$ \\
\hline & & $(2.453)$ & $(2.443)$ & $(2.455)$ \\
\hline \multicolumn{2}{|l|}{$\lambda$} & $-0.502 * * *$ & $-0.530 * * *$ & $-0.525 * * *$ \\
\hline \multicolumn{2}{|l|}{ (loss aversion) } & $(0.188)$ & $(0.189)$ & $(0.182)$ \\
\hline \multicolumn{2}{|l|}{$\alpha$} & $7.048^{*}$ & $6.614^{*}$ & 5.989 \\
\hline \multicolumn{2}{|l|}{ (probability weighting) } & (3.958) & (3.912) & (3.963) \\
\hline \multirow[t]{2}{*}{ Age } & -0.118 & -0.105 & -0.124 & -0.116 \\
\hline & $(0.139)$ & $(0.132)$ & $(0.132)$ & $(0.135)$ \\
\hline \multirow[t]{2}{*}{ Education (Years) } & $-0.726^{* *}$ & $-0.650^{*}$ & $-0.622 *$ & -0.542 \\
\hline & $(0.358)$ & $(0.346)$ & $(0.345)$ & $(0.333)$ \\
\hline \multirow[t]{2}{*}{ Plot Size (Ha) } & $-9.441 * * *$ & $-7.497 * *$ & $-8.151 * *$ & $-8.858 * * *$ \\
\hline & $(3.591)$ & $(3.089)$ & $(3.162)$ & $(3.262)$ \\
\hline \multirow[t]{2}{*}{ Price of Pesticide } & $-0.377 * * *$ & $-0.389 * * *$ & $-0.388 * * *$ & $-0.371 * * *$ \\
\hline & $(0.061)$ & $(0.062)$ & $(0.062)$ & $(0.063)$ \\
\hline \multirow[t]{2}{*}{$\mathrm{Bt}^{\mathrm{a}}$} & $-19.51 * *$ & $-21.48 * *$ & $-21.77 * *$ & $-25.92 * * *$ \\
\hline & $(8.135)$ & $(8.785)$ & $(8.766)$ & $(9.516)$ \\
\hline \multirow[t]{2}{*}{ Experience with Bt (Years) } & 0.99 & 1.084 & $1.147^{*}$ & 1.093 \\
\hline & $(0.649)$ & $(0.681)$ & $(0.682)$ & $(0.679)$ \\
\hline \multirow[t]{2}{*}{ Training $^{\mathrm{b}}$} & & & -3.27 & -2.803 \\
\hline & & & $(2.086)$ & $(2.095)$ \\
\hline \multirow[t]{2}{*}{ Bollworm Severity $^{c}$} & & & & 0.0805 \\
\hline & & & & $(0.050)$ \\
\hline \multirow[t]{2}{*}{ Mirid Severity ${ }^{\mathrm{d}}$} & & & & 0.0438 \\
\hline & & & & $(0.035)$ \\
\hline Observations & 941 & 930 & 930 & 925 \\
\hline R-squared & 0.327 & 0.362 & 0.367 & 0.384 \\
\hline
\end{tabular}

Note: Robust standard errors are listed in parentheses. * significant at the $10 \%$ level; ${ }^{* *}$ significant at the $5 \%$ level; *** significant at the $1 \%$ level. All regressions include village fixed effects. Standard errors are clustered at the individual level. The unit of observation for the regression is the plot. In particular, we have 5 farmers (11 plots) who did not participate in the experiment.

a. Bt Cotton equals 1 if $\mathrm{Bt}$ cotton was planted in the plot, 0 if non-Bt cotton was planted in the plot.

b. Training equals 1 if the farmer had ever attended a training, 0 if he/she never attended a training.

c. It is proxied by an answer to a yield loss perception question: What do you think your potential yield loss will be if you do not control for bollworm? The answer can range from 0 to 100 . The higher value indicates the worse bollworm severity.

d. It is proxied by an answer to a yield loss perception question: What do you think your potential yield loss will be if you do not control for mirids? The answer can range from 0 to 100 . The higher value indicates the worse mirid severity. 
Table 5. OLS Regression of Pesticide Use (Kilogram/Hectare)

\begin{tabular}{|c|c|c|}
\hline & (1) & (2) \\
\hline $\begin{array}{l}\sigma \\
\text { (value function curvature) }\end{array}$ & $\begin{array}{l}7.597 * * * \\
(2.501)\end{array}$ & $\begin{array}{l}7.454 * * * \\
(2.520)\end{array}$ \\
\hline$\lambda$ & $-0.579 * * *$ & $-0.611 * * *$ \\
\hline (loss aversion) & $(0.189)$ & $(0.189)$ \\
\hline$\alpha$ & 5.400 & 4.967 \\
\hline (probability weighting) & (3.915) & (3.874) \\
\hline \multirow[t]{2}{*}{ Age } & -0.113 & -0.103 \\
\hline & $(0.137)$ & $(0.137)$ \\
\hline \multirow[t]{2}{*}{ Education (years) } & -0.357 & -0.398 \\
\hline & $(0.357)$ & $(0.356)$ \\
\hline \multirow[t]{2}{*}{ Plot Size (Ha) } & $-10.24 * * *$ & $-9.495 * * *$ \\
\hline & $(3.693)$ & $(3.629)$ \\
\hline \multirow[t]{2}{*}{ Price of Pesticide } & $-0.456 * * *$ & $-0.450 * * *$ \\
\hline & $(0.087)$ & $(0.086)$ \\
\hline \multirow[t]{2}{*}{ Training } & $-4.676^{*}$ & $-4.975^{*}$ \\
\hline & (2.619) & $(2.704)$ \\
\hline \multirow[t]{2}{*}{ Price of Seed } & 0.017 & \\
\hline & $(0.028)$ & \\
\hline \multicolumn{3}{|l|}{ Source } \\
\hline \multirow[t]{2}{*}{ Seed Companies } & & 3.973 \\
\hline & & $(4.860)$ \\
\hline \multirow[t]{2}{*}{ Village Office } & & -0.279 \\
\hline & & (5.497) \\
\hline \multirow[t]{2}{*}{ Exchange w/ Neighbors } & & 0.323 \\
\hline & & $(5.134)$ \\
\hline \multirow[t]{2}{*}{ Saved Seeds } & & 2.044 \\
\hline & & $(4.750)$ \\
\hline \multirow[t]{2}{*}{ Research Inst } & & -4.963 \\
\hline & & (6.149) \\
\hline \multirow[t]{2}{*}{ Seed Vendors } & & -0.738 \\
\hline & & $(4.280)$ \\
\hline \multirow[t]{2}{*}{ Agri. Extension } & & 2.582 \\
\hline & & $(4.843)$ \\
\hline Observations & 920 & 920 \\
\hline R-squared & 0.352 & 0.359 \\
\hline
\end{tabular}

Note: All non-Bt cotton plots are excluded from the regressions. Robust standard errors are listed in parentheses. * significant at $10 \%$; $* *$ significant at $5 \% ; * * *$ significant at $1 \%$. All regressions include village fixed effects. Standard errors are clustered at the individual level. 
Table 6. OLS Regression of Pesticide Use (Kilogram/Hectare)

\begin{tabular}{lll}
\hline \hline & $(1)$ & $(2)$ \\
\hline$\sigma$ & $6.587^{* * *}$ & $6.755^{* * *}$ \\
(value function curvature) & $(2.166)$ & $(2.226)$ \\
$\lambda$ & $-0.440^{* *}$ & $-0.426^{*}$ \\
(loss aversion) & $(0.204)$ & $(0.209)$ \\
$\alpha$ & 4.497 & 4.181 \\
(probability weighting) & $(5.346)$ & $(5.417)$ \\
Age & -0.154 & -0.157 \\
& $(0.168)$ & $(0.167)$ \\
Education (years) & -0.247 & -0.266 \\
& $(0.283)$ & $(0.286)$ \\
Total Landholing (Ha) & -4.220 & -4.230 \\
& $(2.911)$ & $(2.888)$ \\
Price of Pesticide & $-0.461^{* * *}$ & $-0.460^{* * *}$ \\
& $(0.086)$ & $(0.093)$ \\
Training & $-4.167^{*}$ & $-4.602^{* *}$ \\
& $(2.020)$ & $(1.991)$ \\
Extension Agent $1^{\mathrm{a}}$ & $-6.390^{*}$ & \\
Extension Agent $3^{\mathrm{b}}$ & $(3.626)$ & \\
Observations & & -1.451 \\
R-squared & 311 & $(2.584)$ \\
\hline \hline Note: Robust & 0.32 & 311 \\
\hline
\end{tabular}

Note: Robust standard errors are listed in parentheses. ${ }^{*}$ significant at $10 \%$;* significant at $5 \%$; ** significant at $1 \%$. Unit of observation is at the household level. All traditional cotton plots are excluded when compiling total pesticide use and landholding. All regressions include village fixed effects. Standard errors are clustered at the village level.

a. This variable equals to 1 if the farmer reported having extension agent as number 1 source of information when deiciding how much pesticide to spray

b. This variable equals to 1 if the farmer reported having extension agent as top 3 source of information when deiciding how much pesticide to spray 
Table 7. Robustness Checks for Pesticide Use

\begin{tabular}{llll}
\hline \hline Dependent Variable & $\begin{array}{l}\text { Ln}(\text { Pesticide Use) } \\
(1)\end{array}$ & $\begin{array}{l}\text { Pesticide Expenditure } \\
(\text { Yuan/Ha) }\end{array}$ & $\begin{array}{l}\text { Pesticide Use } \\
(\mathrm{Kg} / \mathrm{Ha})\end{array}$ \\
\hline$\sigma$ & $0.242^{* *}$ & $211.7^{* * *}$ & $6.793^{* * *}$ \\
(value function curvature) & $(0.098)$ & $(69.360)$ & $(2.241)$ \\
$\lambda$ & $-0.0150^{*}$ & $-14.34^{* *}$ & $-0.414^{*}$ \\
(loss aversion) & $(0.008)$ & $(5.686)$ & $(0.206)$ \\
$\alpha$ & 0.142 & 118.100 & 4.274 \\
(probability weighting) & $(0.140)$ & $(112.400)$ & $(5.363)$ \\
Age & -0.004 & -3.235 & -0.155 \\
& $(0.004)$ & $(3.821)$ & $(0.168)$ \\
Education (years) & -0.022 & $-22.22^{*}$ & -0.262 \\
& $(0.013)$ & $(12.020)$ & $(0.288)$ \\
Plot Size (Ha) & $-0.217^{*}$ & $-193.4^{* *}$ & -4.213 \\
Price of Pesticide & $(0.123)$ & $(78.590)$ & $(2.866)$ \\
& $-0.0169^{* * *}$ & & $-0.458^{* * *}$ \\
Experience With Bt (Years) & $(0.002)$ & & $(0.094)$ \\
& 0.035 & 27.780 & \\
Bt & $(0.022)$ & $(19.320)$ & \\
Training & $-0.659^{* * *}$ & $-616.1^{* *}$ & \\
Observations & $(0.216)$ & $(263.600)$ & \\
R-squared & -0.122 & -87.540 & $-4.839^{* *}$ \\
\hline \hline No: Robust san & $(64.880)$ & $(1.898)$ \\
& $(0.081)$ & 930 & 311 \\
& 930 & 0.319 & 0.316 \\
\hline
\end{tabular}

Note: Robust standard errors are listed in parentheses. ${ }^{*}$ significant at $10 \%$; $*$ significant at $5 \%$;** significant at $1 \%$. Unit of observation is at the plot level for Columns 1 and 2 , but it is at the household level for Column 3. All traditional cotton plots are excluded when compiling total pesticide use and landholding for Column 3. In Column 3, the plot size variable is replaced by total landholding. All regressions include village fixed effects. Standard errors are clustered at the village level. 
Table 8. Loss Aversion and Pesticide Use

\begin{tabular}{|c|c|c|}
\hline \multirow[t]{2}{*}{ Dependent Variable } & $\overline{L n}$ (Pesticide Use) & $\begin{array}{l}\text { Pesticide Expenditure } \\
\text { (Yuan/Ha) }\end{array}$ \\
\hline & (1) & (2) \\
\hline$\sigma$ & $5.876^{*}$ & $5.947^{*}$ \\
\hline (value function curvature) & $(2.827)$ & $(2.861)$ \\
\hline$\alpha$ & 5.437 & 4.577 \\
\hline (probability weighting) & $(5.390)$ & $(5.720)$ \\
\hline$\lambda(2$ nd Quartile) & -0.610 & -0.102 \\
\hline $0.83<\lambda<2.02$ & $(3.260)$ & (3.130) \\
\hline$\lambda(3$ rd Quartile) & -1.955 & -1.332 \\
\hline $2.02<\lambda<3.22$ & $(2.764)$ & $(3.205)$ \\
\hline$\lambda$ (4th Quartile) & -2.247 & -1.518 \\
\hline $3.22<\lambda$ & $(2.531)$ & $(2.412)$ \\
\hline$\lambda(\text { (2nd Quartile) })^{*}$ Med Cost ${ }^{\mathrm{a}}$ & & $\begin{array}{l}-1.575 \\
(1.680)\end{array}$ \\
\hline$\lambda(3$ rd Quartile)*Med Cost & & $\begin{array}{l}-1.581 \\
(1.424)\end{array}$ \\
\hline$\lambda(4$ th Quartile)*Med Cost & & $\begin{array}{l}-1.826^{* * * *} \\
(0.458)\end{array}$ \\
\hline Observations & 303 & 303 \\
\hline R-squared & 0.306 & 0.313 \\
\hline
\end{tabular}

Note: Robust standard errors are listed in parentheses. * significant at $10 \%$; $* *$ significant at $5 \%$; *** significant at $1 \%$. Unit of observation is at the household level. We exclude individuals (6 farmers) whose last pesticide poisoning experience occurred in 2006 given that they would not have the chance to adjust their pesticide use after the most recent pesticide poisoning experience. All regressions control for village fixed effects, age, education, landholding $\&$ training. The default group are those who are in the first quartile (least loss averse). Standard errors are clustered at the village level.

a. Med cost equals to all costs (both medical and imputed labor cost) incurred due to last pesticide poisoning episode in 100 Yuan. 